\title{
A Cas-BCAR3 co-regulatory circuit controls lamellipodia dynamics
}

\author{
Elizabeth M. Steenkiste ${ }^{1,2}$, Jason D. Berndt ${ }^{1,3 *}$, Carissa Pilling ${ }^{1 *}$, Christopher Simpkins ${ }^{1}$ \\ and Jonathan A. Cooper ${ }^{1,2}$
}

${ }^{1}$ Division of Basic Sciences, Fred Hutchinson Cancer Research Center, 1100 Fairview Avenue N, Seattle Washington 98109

${ }^{2}$ Molecular and Cellular Biology Program, University of Washington, Seattle, Washington 98195

${ }^{3}$ Present address: Seagen, Bothell, Washington 98021

* Equal contributions

Corresponding author:

Jonathan A. Cooper

office: 206-667-4454

cell: 206-604-6206

email: jcooper@fredhutch.org 


\section{Abstract}

Integrin adhesion complexes regulate cytoskeletal dynamics during cell migration. Adhesion activates phosphorylation of integrin-associated signaling proteins, including Cas (p130Cas, BCAR1), by Src-family kinases. Cas regulates leading-edge protrusion and migration in cooperation with its binding partner, BCAR3. However, it has been unclear how Cas and BCAR3 cooperate. Here, using normal epithelial cells, we find that BCAR3 localization to integrin adhesions requires Cas. In return, Cas phosphorylation, as well as lamellipodia dynamics and cell migration, requires BCAR3. These functions require the BCAR3 SH2 domain and a specific phosphorylation site, Tyr 117, that is also required for BCAR3 downregulation by the ubiquitin-proteasome system. These findings place BCAR3 in a co-regulatory positivefeedback circuit with Cas, with BCAR3 requiring Cas for localization and Cas requiring BCAR3 for activation and downstream signaling. The use of a single phosphorylation site in BCAR3 for activation and degradation ensures reliable negative feedback by the ubiquitin-proteasome system. 


\section{Introduction}

Animal cells migrate by adhesive crawling or amoeboid blebbing (Trepat et al., 2012). During crawling, transmembrane receptors called integrins provide attachment to the extracellular matrix and organize the actin cytoskeleton (Bachir et al., 2017, Legate et al., 2009). Integrin engagement stimulates protrusion of a dynamic leading lamellipodium. Inside the lamellipodium, rearward flowing actin engages with integrin-associated proteins such as talin and vinculin, forming catch bonds, clustering the integrins, and recruiting additional regulatory and scaffold proteins to form transient structures called nascent adhesions (Case et al., 2015, del Rio et al., 2009, Galbraith et al., 2002, Partridge et al., 2006, Puklin-Faucher et al., 2009, Tadokoro et al., 2003). Most nascent adhesions are short-lived, but some mature into focal adhesions at the base of the lamellipodium, anchoring actin stress fibers and resisting the rearward actin flow to increase lamellipodium protrusion. While many aspects of cell migration can be explained by biomechanics, integrin adhesions also activate biochemical signaling molecules, including focal adhesion kinase (FAK), Src-family kinases (SFKs) and small GTPases (Burridge et al., 1992, Huang et al., 1993, Miyamoto et al., 1995, Schaller et al., 1992). Some FAK and SFKdependent phosphorylations regulate adhesion assembly (Pasapera et al., 2010, Stutchbury et al., 2017, Zaidel-Bar et al., 2007), while others coordinate adhesion with lamellipodium dynamics and other aspects of cell biology, such as cell survival (Mitra et al., 2006).

One important adhesion-regulated signaling protein is Cas (Crk-associated substrate, also called p130Cas or BCAR1), which plays critical roles in lamellipodium protrusion, membrane ruffling, adhesion assembly, adhesion turnover, resistance to anoikis and malignant transformation (Honda et al., 1999, Sanders et al., 2005, Sharma et al., 2008, Webb et al., 2004) (reviews (Defilippi et al., 2006, Tikhmyanova et al., 2010)). Cas is activated when SFKs phosphorylate multiple $\mathrm{YxxP}$ sites in an unstructured region near the $\mathrm{N}$ terminus, known as the "substrate domain" (see Figure 1a for a diagram of Cas structure). Phosphorylation recruits adaptor proteins Crk and CrkL together with guanine nucleotide exchange factors (GEFs), C3G and DOCK180, that activate Rap1 and Rac1 respectively (Fonseca et al., 2004, Goldberg et al., 2003, Hasegawa et al., 1996, Kiyokawa et al., 1998, Klemke et al., 1998, Sakai et al., 1994, Sakai et al., 1997, Tanaka et al., 1994). After activation, Rap1 increases talin recruitment to integrins to promote adhesion maturation (Boettner et al., 2009), while Rac1 stimulates polymerization of branched actin structures by WAVE, leading to lamellipodial protrusion and ruffling (Cheresh et al., 1999, DeMali et al., 2002, Ridley 2001, Ridley et al., 1992, Stradal et al., 2004). Cas also stimulates focal adhesion turnover as the cell moves forwards (Ren et al., 2000, 
Rottner et al., 1999, Webb et al., 2004). Thus, Cas is part of a self-reinforcing cycle in which actin polymerization stimulates Cas phosphorylation, which leads to more actin polymerization, lamellipodium protrusion, membrane ruffling and focal adhesion turnover.

While the consequences of Cas phosphorylation are well-understood, it is less clear how Cas phosphorylation is activated. Cas phosphorylation requires integrin-dependent actin polymerization and an intact actin cytoskeleton (Vuori et al., 1996, Vuori et al., 1995, Zhang et al., 2014, Zhao et al., 2016). In vitro, Cas phosphorylation by SFKs is increased when the substrate domain is physically extended, suggesting that Cas may be a mechanosensor (Hotta et al., 2014, Sawada et al., 2006, Tamada et al., 2004). Cas contains N- and C-terminal domains that associate with integrin adhesions and could be involved in extending the substrate domain (Branis et al., 2017, Donato et al., 2010, Harte et al., 1996, Nakamoto et al., 1997, Nojima et al., 1995, Vuori et al., 1995) (Figure 1a). At the $\mathrm{N}$ terminus, an SH3 domain binds adhesion proteins vinculin and FAK (Harte et al., 1996, Janostiak et al., 2014, Polte et al., 1995), while at the C-terminus, a CCH domain binds to adhesion proteins paxillin and ajuba (Pratt et al., 2005, Yi et al., 2002). In addition, the Cas SH3 domain binds to N-WASP via FAK, and N-WASP stimulates actin polymerization and Cas phosphorylation (Kostic et al., 2006, Wu et al., 2004, Zhang et al., 2014). Thus, Cas may be activated by actin flow or when the substrate domain is extended by forces acting on the Cas $\mathrm{N}$ - and $\mathrm{C}$-terminal domains.

Cas is also subject to negative feedback. Phosphorylation of a YDYV sequence near the $\mathrm{CCH}$ domain mediates pY-Cas degradation (Teckchandani et al., 2014). This phosphosite binds to the SH2 domain of SOCS6 (suppressor of cytokine signaling 6), recruiting CRL5 (Cullin 5RING-ligase) and targeting Cas to the ubiquitin-proteasome system. SOCS6 co-localizes with pY-Cas in adhesions at the leading edge of migrating cells where it inhibits adhesion disassembly (Teckchandani et al., 2016). Mutation of the YDYV sequence or knockdown of SOCS6 or the CRL5 scaffold, Cullin 5 (Cul5), stabilizes Cas and increases adhesion disassembly, lamellipodia protrusion and ruffling (Teckchandani et al., 2016, Teckchandani et al., 2014). Thus, while YxxP phosphorylation activates Cas, YDYV phosphorylation provides negative feedback, restraining leading edge dynamics and stabilizing adhesions.

Cas receives additional regulatory input from NSP family proteins, including BCAR3 (breast cancer anti-estrogen resistance 3, also called AND-34, NSP2, Sh2d3b) (Wallez et al., 2012). Cas forms a complex with BCAR3, with the Cas $\mathrm{CCH}$ domain bound to a $\mathrm{CDC} 25 \mathrm{H}$ domain in 
BCAR3 (Figure 1a). BCAR3 and Cas cooperate in many biological assays, with each protein requiring the other. For example, BCAR3 increases Cas phosphorylation and Cas-dependent membrane ruffling, adhesion disassembly, cell migration, cell proliferation (Cai et al., 2003, Cross et al., 2016, Oh et al., 2013, Riggins et al., 2003, Roselli et al., 2010, Schrecengost et al., 2007, Schuh et al., 2010). Like Cas, BCAR3 protects estrogen-dependent breast cancer cells from inhibitory actions of anti-estrogens (van Agthoven et al., 1998). However, it remains unclear how Cas and BCAR3 cooperate. Several lines of evidence suggest that BCAR3 may be regulated by tyrosine phosphorylation. First, it contains an $\mathrm{SH} 2$ domain that binds pY proteins, including the epidermal growth factor (EGF) receptor (Oh et al., 2008) and PTPRA (RPTP $\alpha$ ), a protein phosphatase that activates SFKs and Cas (Sun et al., 2012, von Wichert et al., 2003, Zheng et al., 2000). Second, BCAR3 tyrosine phosphorylation is stimulated by adhesion or serum, although the significance of the phosphorylation is unknown (Cai et al., 1999). These studies suggest that BCAR3 interacts with tyrosine kinases and is phosphorylated, but leave open whether BCAR3 phosphorylation is involved in Cas activation.

Here, we report that we detected BCAR3 in a screen for $\mathrm{pY}$ proteins that are down-regulated by CRL5 and the proteasome. We identified BCAR3 Y117 as a phosphorylation site that recruits SOCS6 and leads to CRL5-dependent degradation. In addition, we found that BCAR3 is needed for single-cell migration and invasion, and for the increased lamellipodial ruffling and collective migration of Cul5-deficient cells. Using gene silencing and mutant analysis, we find that Cas localizes to adhesions independent of BCAR3 but BCAR3 localization to adhesions requires association with Cas. In the adhesion, BCAR3 activates SFKs, Cas phosphorylation, membrane ruffling and cell migration, dependent on both $\mathrm{Y} 117$ and the SH2 domain. BCAR3 and Cas thus form a signaling hub that localizes to active integrins and coordinates actin dynamics under negative control by the ubiquitin-proteasome system. 


\section{Results}

\section{CRL5 regulates BCAR3 protein turnover}

We previously reported that CRL5 inhibits Src activity and Src-dependent transformation of MCF10A epithelial cells, in part by targeting pY proteins such as pYCas for degradation by the ubiquitin-proteasome system (Teckchandani et al., 2014). Because overexpression of Cas alone did not phenocopy CRL5 inhibition (Teckchandani et al., 2014), we infer that CRL5 downregulates additional pY proteins that become limiting when Cas is over-expressed. We sought to identify such $\mathrm{pY}$ proteins by screening for $\mathrm{pY}$ peptides whose abundance increases when Cul5 is inhibited. To this end, control and Cul5-deficient MCF10A cells were lysed under denaturing conditions, proteins were digested with trypsin, and peptides were labeled with isobaric TMT tags for quantitative pY proteomics (Zhang et al., 2007). In one experiment, samples were prepared from control and Cul5-deficient cells that were starved for epidermal growth factor (EGF) for 0, 24 or $72 \mathrm{hr}$. Starvation time had no systematic effect on peptide abundance, so, in a second experiment, we prepared biological triplicate samples from growing control and Cul5deficient cells. Sixteen pY peptides increased significantly in Cul5-deficient cells in both experiments, including pY128 from Cas and pY117 and pY266 from BCAR3 (Figure 1b, Figure 1 - Figure Supplement 1, Supplementary Table). We decided to focus on BCAR3 because Cul5 regulates Cas and Cas binds BCAR3 (Wallez et al., 2012).

The increased quantity of BCAR3 pY peptides in Cul5-deficient cells could result from increased phosphorylation, increased protein level, or both. We used immunoblotting to test whether BCAR3 protein level is regulated by Cul5. BCAR3 protein level increased approximately 4-fold in Cul5-deficient cells, under two different media conditions (Figure 1c). However, RNA levels were unaltered (Figure 1c), consistent with altered protein synthesis or degradation. To measure degradation, we inhibited new protein synthesis with cycloheximide and monitored BCAR3 protein level. BCAR3 half-life was approximately 4 hours in control cells but greater than 8 hours in Cul5-deficient cells (Figure 1d). BCAR3 degradation was inhibited by Cullin neddylation inhibitor MLN4924 or proteasome inhibitor MG132, but not by lysosome inhibitor Bafilomycin (Fig 1e). These results suggest that CRL5 regulates BCAR3 turnover by the ubiquitin-proteasome system and that the increase in BCAR3 pY117 and pY266 in Cul5deficient cells is likely due to an increased availability of BCAR3 protein for phosphorylation rather than, or in addition to, an increase in kinase activity.

\section{BCAR3 regulates epithelial cell migration}


BCAR3 is required for the migration of cancer cells and fibroblasts in single-cell assays (Cross et al., 2016, Schrecengost et al., 2007, Sun et al., 2012) but its importance in single and collective epithelial cell migration is unknown. We inhibited BCAR3 expression in MCF10A cells using siRNA or BCAR3 gene disruption (Figure 2a, Figure 2 - Figure Supplement 1a). BCAR3deficient cells migrated slower than control cells in single-cell migration and invasion assays, regardless of Cul5, suggesting that BCAR3 and CRL5 regulate single-cell migration independently (Figure 2b, c, Figure 2 - Figure Supplement $1 \mathrm{~b}$ and c). In contrast, in a collective migration scratch wound assay, BCAR3 was not required unless Cul5 was depleted (Figure 2d). Moreover, inspection of the wound edge revealed that BCAR3 is also needed for the increased lamellipodia length and ruffling in Cul5-depleted cells (Figure 2e-g). This epistatic relationship is consistent with CRL5 inhibiting BCAR3-dependent migration and lamellipodia under collective conditions, as found before for Cas (Teckchandani et al., 2014). We do not understand which CRL5 substrates regulate single cell migration, but can make use of single-cell assays to test the role of BCAR3 in normal cells, and collective assays to test the role of BCAR3 when it is over-expressed or activated by Cul5 depletion.

\section{CRL5 directly targets BCAR3 through SOCS6}

CRL5 promotes ubiquitination and degradation of substrate proteins bound to adaptor proteins (Okumura et al., 2016). CRL5 adaptors include SOCS family proteins, which contain SH2 domains for binding to $\mathrm{pY}$. To test whether SOCS proteins bind BCAR3, we transiently expressed T7-tagged SOCS proteins and assayed binding to endogenous BCAR3 by immunoprecipitation and immunoblotting. BCAR3 specifically co-precipitated with SOCS6, the same adaptor that binds Cas (Figure 3a) (Teckchandani et al., 2014). Accordingly, SOCS6 loss of function in MCF10A cells increased BCAR3 steady-state protein levels and decreased the rate of BCAR3 turnover (Figure 3b,c). Together, these results suggest that CRL5 ${ }^{\mathrm{SOCS6}}$ mediates BCAR3 turnover.

Since BCAR3 and Cas bind each other and both are bound and regulated by SOCS6, it is possible that SOCS6 binds BCAR3 indirectly, through Cas. We tested this possibility by two strategies (Figure 3d). First, we used a BCAR3 mutant, L744E/R748E, called here BCAR3 ${ }^{\mathrm{EE}}$, that does not bind Cas (Wallez et al., 2014). This mutation inhibited binding to Cas but not SOCS6 (Figure 3e). Second, we found that BCAR3-SOCS6 binding occurred in cells from which Cas had been depleted with siRNA (Figure 3f). Collectively, these data suggest that SOCS6 binds to BCAR3 independently of Cas. 


\section{SOCS6 binds BCAR3 pY117}

We considered that SOCS6 might bind BCAR3 through pY-dependent or -independent interactions. Pervanadate, a cell-permeable phosphotyrosine phosphatase inhibitor, increased BCAR3-SOCS6 association, suggesting pY dependence (Figure 4a). In addition, disrupting the SOCS6 SH2 domain by deletion $(\Delta \mathrm{C})$ or point mutation (R407K) inhibited binding to BCAR3 (Figure 4b). This suggests that the SOCS6 SH2 domain binds pY-BCAR3. Serum or adhesion stimulates tyrosine phosphorylation of BCAR3 in mouse fibroblasts (Cai et al., 1999), but the specific sites have not been identified. High-throughput $p Y$ proteomics surveys have identified phosphorylation of BCAR3 at tyrosine residues 42, 117, 212, 266 and 429 in over 25 mouse and human cell lines (Hornbeck et al., 2019). We tested whether these sites were required for binding SOCS6 using site-directed mutagenesis (Figure 4c). BCAR3 ${ }^{\mathrm{F} 5}$, in which all five tyrosines were changed to phenylalanines, was unable to bind SOCS6 (Figure 4d. By mutating each pY site individually, we found that $\mathrm{Y} 117$ is necessary to bind SOCS6 (Figure 4d). Furthermore, mutating all sites except Y117 (42, 212, 266 and 429) had little effect on SOCS6 binding (BCAR3 $^{\mathrm{F} 4}$ mutant, Figure $4 \mathrm{e}$ ). These results support a model in which phosphorylation of BCAR3 at $\mathrm{Y} 117$ is both necessary and sufficient to bind the SOCS6 SH2 domain.

\section{CRL5-dependent BCAR3 turnover requires Y117 and Cas association, but not the SH2 domain or other tyrosine residues}

To test whether $\mathrm{Y} 117$ or other domains of BCAR3 are required for CRL5-dependent BCAR3 protein turnover, we measured the effect of various mutations on the level of tagged BCAR3 protein in control and Cul5-deficient cells. To avoid possible artifacts due to over-expression, we used a doxycycline-inducible promoter (Baron et al., 1997). MCF10A cells were first transduced to express the reverse tet transactivator (rtTA), and then transduced to express SNAP-V5tagged wildtype or mutant BCAR3 under control of the tet operator. Cells were treated with doxycycline (dox) to induce wildtype or mutant BCAR3 expression, with or without knocking down endogenous BCAR3 with an siRNA targeting the 3' UTR.

We first examined the role of $\mathrm{Y} 117$ in BCAR3 turnover. BCAR3 ${ }^{\mathrm{Y} 117 \mathrm{~F}}$ was expressed at approximately two-fold higher level than $\mathrm{BCAR} 3^{\mathrm{WT}}$ at the same concentration of dox (Figure $5 \mathrm{a}$ ). Moreover, depleting Cul5 increased the level of BCAR3 ${ }^{\mathrm{WT}}$ more than 2-fold while the level of BCAR3 $^{\mathrm{Y} 117 \mathrm{~F}}$ was unchanged (Figure $5 \mathrm{~b}$ ), suggesting that CRL5 regulates BCAR3 protein level dependent on $\mathrm{Y} 117$. BCAR3 ${ }^{\mathrm{F} 4}$, which contains $\mathrm{Y} 117$ but not four other tyrosine phosphorylation 
sites, was also regulated by CRL5 (Figure 5c). These results are consistent with SOCS6 binding to pY117 and targeting BCAR3 for CRL5-dependent degradation.

We extended this approach to test the importance of the BCAR3 SH2 domain and Cas binding for degradation. To inactivate the BCAR3 SH2 domain, we created an arginine to lysine at residue 177 (R177K), which lies in the consensus FLVRES motif and is required to bind the $\mathrm{pY}$ phosphate (Jaber Chehayeb et al., 2020, Marengere et al., 1994). Cul5-depletion increased the level of BCAR3 ${ }^{\mathrm{R} 177 \mathrm{~K}}$ (Figure $5 \mathrm{~d}$ ), suggesting this mutant is still phosphorylated at $\mathrm{Y} 117$ and targeted by CRL5. In contrast, BCAR3 ${ }^{\mathrm{EE}}$, which binds SOCS6 (Figure 3e) but not Cas (Figure $3 e$ and Figure 5 - figure supplement 1 ), was not regulated by CRL5. Taken together, these results suggest that $\mathrm{pY} 117$ and Cas association are required for CRL5-dependent turnover of BCAR3 expressed at near endogenous level.

\section{Lamellipodial ruffling and cell migration require BCAR3 Y117, SH2 domain and Cas association}

Over-expression of BCAR3 in fibroblasts and breast cancer cells stimulates Cas-dependent functions, such as lamellipodia ruffling (Cai et al., 2003, Wallez et al., 2014, Wilson et al., 2013). Similarly, BCAR3 ${ }^{\mathrm{WT}}$ increased membrane ruffling when over-expressed in MCF10A cells (Figure 6a). Since BCAR3 ${ }^{\mathrm{Y} 117 \mathrm{~F}}$ accumulates to higher levels, we suspected it may be more active in biological assays. However, contrary to expectations, ruffling was induced by over-expressing $\mathrm{BCAR3}^{\mathrm{F} 4}$ but not BCAR3 ${ }^{\mathrm{Y} 117 \mathrm{~F}}, \mathrm{BCAR}^{\mathrm{R} 177 \mathrm{~K}}$ or BCAR3 ${ }^{\mathrm{EE}}$ (Figure 6a). Similarly, when endogenous BCAR3 is depleted, BCAR3 ${ }^{\mathrm{WT}}$ and $\mathrm{BCAR}^{\mathrm{F} 4}$, but not BCAR3 ${ }^{\mathrm{Y} 117 \mathrm{~F}}, \mathrm{BCAR}^{\mathrm{R} 177 \mathrm{~K}}$ or BCAR3 ${ }^{\mathrm{EE}}$, were able to rescue single-cell migration (Figure $6 b$ ) and increase collective migration and lamellipodia ruffling of Cul5-deficient cells (Figure 6c). This suggests that $Y 117$ has two roles. First, $\mathrm{Y} 117$ is the main phosphorylation site for BCAR3 down-regulation. Second, it is also the main phosphorylation site for BCAR3 function, cooperating with the $\mathrm{SH} 2$ domain and Cas to promote single-cell and collective migration and lamellipodial dynamics in the presence and absence of Cul5.

\section{Cas recruits BCAR3 to integrin adhesions}

These findings raise the question of how BCAR3 Y117, SH2 domain, and Cas binding cooperate to regulate MCF10A cell motility. Previous studies in cancer cells and fibroblasts found that BCAR3 localizes to integrin adhesions (Cross et al., 2016, Sun et al., 2012) and that BCAR3 over-expression can increase Cas in membrane ruffles (Riggins et al., 2003). Increased 
Cas could then activate lamellipodia dynamics through the established Cas/Crk/DOCK180/Rac pathway (Klemke et al., 1998, Sakai et al., 1994, Sanders et al., 2005, Sharma et al., 2008). These findings suggest that BCAR3's Y117 and SH2 domain may be needed for BCAR3 to correctly localize Cas. To explore this possibility, we monitored the effect of depleting BCAR3 on Cas localization and the effect of depleting Cas on BCAR3 localization. We were unable to detect endogenous BCAR3 by immunofluorescence with available antibodies, so we expressed SNAP-V5-BCAR3 at near endogenous levels and detected the fusion protein with SNAP ligand (Grimm et al., 2015, Keppler et al., 2003). Both Cas and BCAR3 ${ }^{W T}$ localized to adhesions in the leading edge of collectively migrating cells. Cas remained in adhesions when BCAR3 was depleted (Figure 7a). In contrast, BCAR3 was absent from adhesions when Cas was depleted (Figure 7b). Thus, BCAR3 requires Cas to localize in adhesions, and not vice versa. Consistently, all BCAR3 mutants that bound Cas were present in adhesions (Figure 8a, b, Figure 5 - Figure Supplement 1). Together, these results suggest that Cas localizes to adhesions independent of BCAR3 and that Cas brings BCAR3 to adhesions by binding through their $\mathrm{CCH}$ and $\mathrm{CDC} 25 \mathrm{H}$ domains.

\section{BCAR3 activates Cas, dependent on BCAR3 Y117 and SH2 domain}

Since BCAR3 does not regulate Cas localization, what is the function of $\mathrm{Y} 117$ and the SH2 domain? We considered that BCAR3 may activate Cas. To monitor Cas activity, we used antibodies to pY165, one of the repeated YxxP motifs in Cas that recruit Crk (Fonseca et al., 2004, Sakai et al., 1994, Songyang et al., 1993). Cas pY165 in leading edge adhesions was abolished by SFK inhibition or Cas depletion, consistent with Cas activity (Figure 8 - figure supplement 1). Notably, Cas activity was inhibited when BCAR3 was depleted (Figure 8 - figure supplement 2a). As expected, BCAR3 ${ }^{\mathrm{WT}}$ and $\mathrm{BCAR} 3^{\mathrm{F} 4}$ rescued Cas activity in BCAR3-depleted cells (Figure $8 \mathrm{a}, \mathrm{c}$ ). However, Cas activity was not rescued by $\mathrm{BCAR}^{\mathrm{Y} 117 \mathrm{~F}}, \mathrm{BCAR}^{\mathrm{R} 177 \mathrm{~K}}$ or $\mathrm{BCAR3}^{\mathrm{EE}}$, even though Cas was still present (Figure 8a, c, Figure 8 - Figure Supplement 3). Cas activation in adhesions correlated with the rescue of ruffling and migration (Figures $6 \mathrm{~b}$ and 8). This suggests that BCAR3 not only has to be bound to Cas but also needs $\mathrm{Y} 117$ and its SH2 domain to activate Cas and promote downstream signaling. To test whether BCAR3 activates Cas specifically or phosphorylation more generally, we also stained for FAK pY397 and pY861. The former is a FAK autophosphorylation site and is phosphorylated by SFKs (Mitra et al., 2006). We found that BCAR3 depletion did not inhibit FAK autophosphorylation at pY397 but did inhibit FAK pY861 (Figure 8 - Figure Supplement 2b and c), consistent with a general role of BCAR3 in stimulating SFKs in adhesions. Taken together, these results suggest that BCAR3 is 
brought to integrin adhesions by binding to Cas, where it uses its $\mathrm{Y} 117$ and $\mathrm{SH} 2$ domain to activate SFKs, Cas and downstream signaling, leading to lamellipodial ruffling and migration.

\section{Discussion}

Cell migration requires biophysical and biochemical signaling between the leading edge and adhesion complexes to coordinate adhesion assembly and disassembly with actin polymerization, anchorage of stress fibers and generation of traction forces (Trepat et al., 2012). Our results address one aspect of this complicated process: the linkage between integrin engagement and lamellipodial extension. Previous studies have found that Cas and BCAR3 synergize for lamellipodium ruffing and cell migration, but they also synergized for protein expression, making the mechanism unclear (Cai et al., 1999, Cross et al., 2016, Riggins et al., 2003, Schrecengost et al., 2007, Wallez et al., 2014). Here, using loss-of-function approaches, we find that there is positive feedback between Cas and BCAR3 phosphorylation, and dual negative feedback on both proteins by the ubiquitin-proteasome system.

Our results support a multi-step model (Figure 9). First, Cas associates with active integrin adhesion complexes near the leading edge of migrating cells through its $\mathrm{N}$ and $\mathrm{C}$ terminal localization signals. BCAR3 is recruited to adhesions by Cas. Since most BCAR3 in the cell is complexed with Cas (Cross et al., 2016), the two proteins are likely recruited jointly, via localization signals on Cas. BCAR3 then stimulates SFKs and Cas phosphorylation in a mechanism that requires BCAR3 SH2 and $\mathrm{Y} 117$ but not four other phosphorylation sites. Cas phosphorylation then drives membrane ruffling, presumably utilizing the well-documented mechanisms involving Crk, DOCK180 and Rac (Cheresh et al., 1999, Klemke et al., 1998, Sakai et al., 1994, Sanders et al., 2005, Schaller et al., 1995, Sharma et al., 2008). Thus, the BCAR3 Y117 and SH2 provide a critical switch to activate Cas. Our results also suggest that phosphorylation at Y117 promotes SOCS6 binding and targets BCAR3 for ubiquitination and degradation by the CRL5 E3 ubiquitin ligase. pY-Cas is targeted by CRL5 $5^{\text {socs6 }}$ binding to its pYDYV motif (Teckchandani et al., 2014). Ubiquitination likely occurs within the adhesion (Teckchandani et al., 2016). Ubiquitination and degradation of either protein is expected to terminate signaling until new Cas and BCAR3 molecules are recruited from the cytosol, providing double insurance against excess activity.

Where is $\mathrm{Y} 117$ phosphorylated and how does it activate SFKs? We suspect that phosphorylation may occur in adhesions, because BCAR3 ${ }^{\mathrm{EE}}$, which doesn't localize to 
adhesions, is not subject to pY117-dependent turnover by CRL5. However, we have been unable to generate a phospho-specific antibody with the sensitivity and specificity to localize pY117 BCAR3 in cells. After Y117 is phosphorylated, we infer that BCAR3 activates SFKs in adhesions to phosphorylate Cas and FAK. Indeed, previous studies reported SFK activation by BCAR3 (Riggins et al., 2003, Schuh et al., 2010, Sun et al., 2012). One mechanism involves pY-PTPRA binding to the BCAR3 SH2 domain and bringing the BCAR3-Cas complex to adhesions where Cas is phosphorylated by SFKs (Sun et al., 2012). Since PTPRA is able to activate SFKs (Ponniah et al., 1999, Su et al., 1999, Zheng et al., 2000), this is an attractive model. However, in our studies, the BCAR3 SH2 domain is not needed to localize either BCAR3 or Cas, suggesting that Cas-BCAR3 would bring PTPRA to adhesions rather than vice versa. In addition, PTPRA depletion does not inhibit Cas Y165 phosphorylation (data not shown). An alternative is that $\mathrm{pY} 117$ binds the $\mathrm{SH} 2$ domain of an SFK or an unidentified protein that activates SFKs. The Y117 sequence is conserved across vertebrates and a homologous residue is present in Shep1, a second NSP family protein that activates Cas (Roselli et al., 2010). However, the sequence does not suggest which SH2 domain may bind other than SOCS6 (Krebs et al., 2002, Simo et al., 2013, Teckchandani et al., 2014, Zadjali et al., 2011) (Figure 9 - Figure Supplement 1). The presence of a positively charged residue two residues after the phosphosite would inhibit binding to SFKs (Songyang et al., 1993). Therefore, pY117 may bind another $\mathrm{SH} 2$ protein that activates SFKs, or may stimulate Cas phosphorylation by an allosteric mechanism or by altering binding to other charged molecules, such as membrane phospholipids.

Our results reveal that BCAR3 $\mathrm{Y} 117$ is required for both signaling and degradation. This means that BCAR3 activation triggers BCAR3 degradation in a negative feedback loop. The dual use of a single site for activation and degradation resembles $\mathrm{Y} 198$ of the neuron migration protein Dab1, which binds downstream signaling molecules and also recruits SOCS6/7 for CRL5dependent degradation (Simo et al., 2013). Mutating the SOCS-binding site in BCAR3 or Dab1 generates a non-functional protein that accumulates at higher level. In contrast, the SOCS6binding site in Cas is not needed for downstream signaling, so mutating the site causes increased levels of an active protein and a dominant gain-of-function phenotype (Teckchandani et al., 2014).

Our finding that BCAR3 is subject to complex post-translational regulation may be helpful in reconciling the observation that BCAR3 over-expression in cell culture increases transformed 
phenotypes whereas BCAR3 RNA expression correlates with favorable outcomes in patients (Guo et al., 2014, Wallez et al., 2012, Zhang et al., 2018). In addition to the phosphorylationdependent mechanism investigated here, a previous study showed that TGF $\beta$ stimulates proteasomal degradation of BCAR3 (Guo et al., 2014), and over-expressed BCAR3 and Cas appear to stabilize each other in breast cancer cells, dependent on their mutual binding (Wallez et al., 2014). Changes in BCAR3 protein stability or phosphorylation state might influence BCAR3 activity in patients, but that such regulation at the protein level might not be accounted for when correlating patient outcomes with gene expression. Thus, further study is required to understand mechanisms of BCAR3 regulation and how mis-regulation may contribute to disease progression.

\section{Materials and Methods}

\section{Plasmids}

pMXpuroll and pMXpuroll-shCul5 plasmids were made as previously described (Teckchandani et al., 2014). pLKO.1-nontarget small hairpin RNA (shRNA) control vector (SHC002) and pLKO.1-shSOCS6 (TRCN0000284351) were purchased (Sigma Aldrich).

pCAG-T7-mSOCS1, pCAG-T7-mSOCS2, pCAG-T7-mSOCS3, pCAG-T7-mSOCS4, pCAG-T7mSOCS5, pCAG-T7-mSOCS6, pCAG-T7-mSOCS7, and pCAG-T7-mCisH were made as previously described (Simo et al., 2013, Teckchandani et al., 2014). All pCAG-T7-SOCS plasmids used in this work have LC-QQ mutations in the SOCS box to prevent binding to CRL5, and were made using PfuTurbo DNA polymerase to perform site-directed mutagenesis followed by Dpnl digestion. pCAG-T7-mSOCS6 R407K was made as previously described (Teckchandani et al., 2016). pCAG-T7-mSOCS6 $\Delta$ C was made by PCR amplifying codons 1381 of mSOCS6 using a 5' primer complementary to the T7 tag and a 3' primer that inserts a stop codon and a Notl site after codon 381. The PCR product was inserted into pCAG-T7SOCS6 by BamH1/Notl restriction digest and ligation.

pCMV-SPORT6-mBCAR3 was purchased from the Harvard Plasmid Database (MmCD00318547). pcDNA5-3xFlag-mBCAR3 FRT/TO was made by Gateway cloning. mBCAR3 was PCR amplified with flanking attB sites from pCMV-SPORT6-mBCAR3 and inserted into pDONR221 with a BP reaction (Thermo Fisher Scientific). pDEST-5'-3xFlagpcDNA FRT/TO was a kind gift of Dr. Anne-Claude Gingras. pDONR221-mBCAR3 was moved into pDEST-5'-3xFlag-pcDNA FRT/TO with a LR reaction (Thermo Fisher Scientific). 
pLX304-hBCAR3-V5 was obtained from the human ORFeome version 8.1 Entry clone collection (Yang et al., 2011). pLX304-hBCAR3-F5-V5 was made by Gibson Assembly (New England Biolabs). A gBlock (Integrated DNA Technologies) containing BCAR3 Y42F, Y117F, Y212F, Y266F and Y429F mutations was assembled into pLX304-hBCAR3-V5.

rtTA-N144 was a gift from Andrew Yoo (Addgene plasmid \# 66810).

pLTRE3G-SNAP-V5-hBCAR3 was made as follows. A gBlock containing sequence for SNAPV5 tags was inserted into pLenti CMVTRE3G eGFP Blast (w818-1) (gift of Eric Campenau, Addgene \#27568) at the Agel restriction site using Gibson Assembly to make pLTRE3G-SNAPV5-eGFP. hBCAR3 was PCR amplified with flanking Agel and Xbal sites and inserted into Agel and Xbal-digested pLTRE3G-SNAP-V5-eGFP to make pLTRE3G-SNAP-V5-hBCAR3.

pLTRE3G-SNAP-V5-hBCAR3 mutants were made as follows. Single mutants Y42F, Y212F, Y266F, Y429F, R177K, and double mutant EE (L744E/R748E) were made by site-directed mutagenesis with Q5 polymerase (New England Biolabs) and Dpn1 digestion. The Y117F mutant was made by Gibson Assembly. A gBlock containing the BCAR3 Y117F mutation was assembled into pLTRE3G-SNAP-V5-hBCAR3 WT. pLTRE3G-SNAP-V5-hBCAR3 F5 was made by BamHI restriction digest of pLTRE3G-SNAP-V5-hBCAR3 Y42F, discarding the region between codon 107 and 763 and inserting the corresponding region from pLX304-hBCAR3-F5V5. pLTRE3G-SNAP-V5-hBCAR3 F4 was made by PshAl restriction digest of pLTRE3G-SNAPV5-hBCAR3 F5, discarding the region between codon 67 and 163 inserting the corresponding region from pLTRE3G-SNAP-V5-hBCAR3 WT.

\section{Cell lines}

MCF10A cells were cultured in growth medium (DMEM/F12 (Thermo Fisher Scientific) supplemented with $5 \%$ horse serum (Thermo Fisher Scientific), $0.1 \mu \mathrm{g} / \mathrm{ml}$ cholera toxin (EMD Millipore), $10 \mu \mathrm{g} / \mathrm{ml}$ insulin (Thermo Fisher Scientific), $0.5 \mu \mathrm{g} / \mathrm{ml}$ hydrocortisone (Sigma-Aldrich), and $20 \mathrm{ng} / \mathrm{ml}$ EGF (Thermo Fisher Scientific)). Indicated experiments used assay media (DMEM/F12, 2\% horse serum, $0.1 \mu \mathrm{g} / \mathrm{ml}$ cholera toxin, $10 \mu \mathrm{g} / \mathrm{ml}$ insulin, $0.5 \mu \mathrm{g} / \mathrm{ml}$ hydrocortisone, and $0 \mathrm{ng} / \mathrm{ml}$ EGF). The cells were passaged using $0.02 \%$ trypsin in PBS/EDTA. Trypsin was inactivated with an equal volume of DMEM/10\% FBS and cells were harvested by 
centrifugation before resuspending in growth media. HeLa and 293T cells were grown in DMEM/10\% FBS and passaged with trypsin as above.

MCF10A empty vector (EV) and shCul5 cells were made as previously described (Teckchandani et al., 2014). MCF10A shControl and shSOCS6 cells were made as follows. Viruses containing pLKO.1-control and pLKO.1-shSOCS6 were packaged using HEK 293T cells and MCF10A cells were infected. Stable cell lines were selected using $4 \mu \mathrm{g} / \mathrm{mL}$ puromycin.

BCAR3-/- MCF10A cells were made as follows. Early passage MCF10A cells were serially diluted and subclones were grown and characterized. Clone J8 was selected for its epithelial morphology. The J8 clonal cell line was infected with lentiCRISPR v2 (a gift from Feng Zhang; Addgene plasmid \# 52961), lacking or containing guide RNA against BCAR3. pLCRISPRv2sgRNA-hBCAR3(30) and (31) were made by cloning annealed oligos (5'CACCGTCAGAGAGCTACCTGCCGAT-3' or 5'-CACCGCCCGAAACATACCAATCGGC-3') into the BsmBI site of plentiCRISPRv2. Potential knockouts were isolated by single cell expansion. Validation of $B C A R 3$ knockout was done through genomic DNA isolation, PCR, and sequencing, as well as Western blotting.

MCF10A dox-inducible SNAP-V5 BCAR3 cells were made as follows. Viruses containing rtTAN144 were packaged using 293T cells and used to infect MCF10A cells. A stable line was selected using $50 \mu \mathrm{g} / \mathrm{mL}$ hygromycin. The MCF10A cell line stably expressing rtTA was then infected with viruses containing one of the pLTRE3G-SNAP-V5 constructs (pLTRE3G-SNAPV5-eGFP, pLTRE3G-SNAP-V5-BCAR3 WT, Y42F, Y117F, Y212F, Y266F, Y429F, F5, F4, $\mathrm{R} 177 \mathrm{~K}$, or EE). Stable lines were selected using $10 \mu \mathrm{g} / \mathrm{mL}$ blasticidin. Each cell line was hygromycin resistant and blasticidin resistant, however not all cells within each line expressed the SNAP-V5-containing construct following induction with $50-100 \mathrm{ng} / \mathrm{mL}$ dox for $48-72$ hours. To remove non-inducible cells, dox-treated cells were treated with $100 \mathrm{nM}$ JaneliaFluor cp646JFSNAP-ligand (Lavis Lab, Janelia Farms) (Grimm et al., 2015) for 1 hour, washed three times with PBS, incubated in ligand-free growth media for an hour and positive cells were sorted and harvested by FACS using the APC channel to detect cp646JF. 


\section{Antibodies and Reagents}

\begin{tabular}{|c|c|c|c|}
\hline Antibody & Supplier & Catalog & Dilution \\
\hline rabbit anti-BCAR3 & Bethyl & A301-671A-M & Western (1:2000) \\
\hline rabbit anti-Cas (C-20) & Santa Cruz & sc-960 & Western $(1: 1000)$ \\
\hline mouse anti-Cas & BD Biosciences & 610271 & Western $(1: 5000)$ \\
\hline mouse anti-Cas & Santa Cruz & sc-20029 & IF $(1: 100)$ \\
\hline rabbit anti-pY165 Cas & Cell Signaling & 4015S & IF (1:200) \\
\hline rabbit anti-Cullin5 & Abcam & ab184177 & Western $(1: 1000)$ \\
\hline rabbit anti-pY397 FAK & Fisher & $44-624 G$ & IF (1:200) \\
\hline rabbit anti-pY861 FAK & Fisher Scientific & $44-626 G$ & IF $(1: 200)$ \\
\hline rabbit anti-GAPDH (0411) & Santa Cruz & sc-47724 & Western $(1: 1000)$ \\
\hline mouse anti-vinculin & Sigma & V9131 & Western $(1: 10000)$ \\
\hline mouse anti-paxillin & BD Biosciences & 610051 & IF $(1: 200)$ \\
\hline sheep anti-paxillin & R\&D Systems & AF4259 & IF (1:200) \\
\hline mouse anti-FLAG & Sigma & F1804 & Western $(1: 1000)$ \\
\hline mouse anti-T7 & EMB Biosciences & $69522-4$ & $\begin{array}{l}\text { Western }(1: 5000) \\
\text { IP }\end{array}$ \\
\hline rabbit anti-V5 & Bethyl & A190-120A & $\begin{array}{l}\text { Western }(1: 5000) \\
\text { IP }\end{array}$ \\
\hline $\begin{array}{l}\text { AlexaFluor } 488 \text { goat anti-rabbit } \\
\lg (\mathrm{H}+\mathrm{L})\end{array}$ & Invitrogen & A11008 & IF $(1: 1000)$ \\
\hline $\begin{array}{l}\text { AlexaFluor } 647 \text { goat anti- } \\
\text { mouse IgG }(\mathrm{H}+\mathrm{L})\end{array}$ & Invitrogen & A28181 & IF $(1: 1000)$ \\
\hline $\begin{array}{l}\text { AlexaFluor } 647 \text { goat anti- } \\
\text { sheep lgG }(\mathrm{H}+\mathrm{L})\end{array}$ & Invitrogen & A21448 & IF $(1: 1000)$ \\
\hline
\end{tabular}


Reagents used: cycloheximide (Sigma), epidermal growth factor (Invitrogen), MLN4924 (Active Biochem), MG132 (Fisher Scientific), bafilomycin A, doxycycline (Fisher Scientific).

\section{Mass spectrometry}

MCF10A EV and shCul5 cells were grown in 15-cm plates, two plates per condition, to approximately $80 \%$ confluence, washed in PBS, and lysed in $3 \mathrm{~mL}$ per plate of ice-cold $8 \mathrm{M}$ urea containing $1 \mathrm{mM}$ sodium orthovanadate. Proteins were reduced, alkylated and digested with trypsin as described (Zhang et al., 2005). Peptide labeling with iTRAQ reagents (TMT 6plex, Themo Fisher Scientific) was performed according to the manufacturer's instructions, using $400 \mu \mathrm{g}$ of each sample. After reaction, the six samples were combined and concentrated under vacuum. For immunoprecipitation, protein $\mathrm{G}$ agrarose (60 $\mu$, Millipore) was incubated with anti-phosphotyrosine antibodies (12 $\mu \mathrm{g}$ 4G10 (Millipore), $12 \mu \mathrm{g}$ PT66 (Sigma) and $12 \mu \mathrm{g}$ PY100 (Cell Signaling Technology) for 8 hours at $4{ }^{\circ} \mathrm{C}$ with rotation, then washed with $400 \mu$ IP buffer (100 mM Tris HCl, $100 \mathrm{mM} \mathrm{NaCl}$, and $1 \%$ Nonidet P-40, pH 7.4). The TMT-labeled peptides were resuspended in $400 \mu \mathrm{IP}$ buffer and $\mathrm{pH}$ adjusted to 7.4, then mixed with the antibody-conjugated protein $\mathrm{G}$ agarose overnight at $4{ }^{\circ} \mathrm{C}$ with rotation. The antibody beads were spun down and the supernatant saved. The beads were washed with $400 \mu$ IP buffer then four rinses with $100 \mathrm{mM}$ Tris $\mathrm{HCl} \mathrm{pH} 7.4$ before elution with $70 \mu \mathrm{l}$ of $100 \mathrm{mM}$ glycine, $\mathrm{pH} 2.0$ for 30 minutes at $25^{\circ} \mathrm{C}$. Offline immobilized metal affinity chromatography (IMAC) was used to further enrich for phosphotyrosine peptides (Zhang et al., 2005).

Peptides were loaded on a precolumn and separated by reverse phase HPLC using an EASYnLC1000 (Thermo) over a 140-minute gradient from $100 \%$ solvent $\mathrm{A}\left(\mathrm{H}_{2} \mathrm{O} / \mathrm{CH}_{3} \mathrm{COOH}, 99: 1\right.$ (v/v)) to $30 \% \mathrm{~A}: 70 \% \mathrm{~B}\left(\mathrm{H}_{2} \mathrm{O} / \mathrm{CH}_{3} \mathrm{CN} / \mathrm{CH}_{3} \mathrm{COOH}, 29: 70: 1(\mathrm{v} / \mathrm{v})\right)$. Eluted peptides were injected using nanoelectrospray into a QExactive Pluss mass spectrometer (Thermo) in data-dependent mode. The parameters for full scan MS were: resolution of 70,000 across 350-2000 m/z, AGC $3 \mathrm{e}^{6}$, and maximum IT $50 \mathrm{~ms}$. The full MS scan was followed by MS/MS for the top 10 precursor ions in each cycle with a NCE of 34 and dynamic exclusion of $30 \mathrm{~s}$. Raw mass spectral files (.raw) were searched using Proteome Discoverer (Thermo) and Mascot version 2.4.1 (Matrix Science). Mascot search parameters were: 10 ppm mass tolerance for precursor ions; $15 \mathrm{mmu}$ for fragment ion mass tolerance; 2 missed cleavages of trypsin; fixed modifications were carbamidomethylation of cysteine and TMT 6plex modification of lysines and peptide N-termini; variable modifications were methionine oxidation, tyrosine, serine and threonine phosphorylation. TMT quantification was obtained using Proteome Discoverer and isotopically 
corrected per manufacturer's directions, and normalized to the mean relative protein quantification ratios obtained from the total protein analysis $(0.2 \%$ of the unbound peptides from the phosphotyrosine peptide immunoprecipitation). Mascot peptide identifications, phosphorylation site assignments and quantification were verified manually with the assistance of CAMV (Curran et al., 2013). Validated data were analyzed in Excel using a one-sided twosample equal variance Student t-test.

\section{siRNA Transfection}

MCF10A cells were trypsinized and seeded in growth medium into a 12-well plate so as to be $50 \%$ confluent after attaching. A mixture of 50 pmol siRNA, $1.25 \mu$ Lipofectamine 2000 (Invitrogen) in Optimem medium (Invitrogen) was added to the newly plated MCF10A cells and left for the cells to attach overnight. The next day the media was changed to fresh growth media. A second siRNA transfection was done 48 hours after the first transfection using the same protocol scaled up to use a 6 -well plate (125 pmol siRNA) or scaled down to use a 96-well plate (for migration assays). One day later, cells from the 6-well dish were transferred to 4-well plates containing 12-mm coverslips for microscopy, or 12-well plates for protein analysis. Doxycline was added as needed at $10 \mathrm{ng} / \mathrm{mL}$ for $2-3$ days before analysis. Cells were either lysed 48 hours after the second transfection or assays were performed as described.

\begin{tabular}{|c|c|c|c|c|}
\hline siRNA & Target Sequence & Source & Notes & Catalog \\
\hline $\begin{array}{l}\text { Control } \\
\text { siRNA }\end{array}$ & 5'-AATTCTCCCGAACGTGTCACGT-3' & Qiagen & & 1027310 \\
\hline $\begin{array}{l}\text { SOCS6 } \\
\text { siRNA Pool }\end{array}$ & $\begin{array}{l}\text { 5'-TAGAATCGTGAATTGACATAA-3' } \\
\text { 5'-CAGCTGCGATATCAACGGTGA-3' } \\
\text { 5'-TTGATCTAATTGAGCATTCAA-3' } \\
\text { 5'-CGGGTACAAATTGGCATAACA-3' }\end{array}$ & Qiagen & & $\begin{array}{l}\text { SI00061383 } \\
\text { SI03068359 } \\
\text { SI00061369 } \\
\text { SI00061376 }\end{array}$ \\
\hline $\begin{array}{l}\text { Cul5 siRNA } \\
\text { Pool }\end{array}$ & $\begin{array}{l}\text { 5'-GACACGACGTCTTATATTA-3' } \\
\text { 5'-CGTCTAATCTGTTAAAGAA-3' } \\
\text { 5'-GATGATACGGCTTTGCTAA-3' } \\
\text { 5'-GTTCAACTACGAATACTAA-3' }\end{array}$ & $\begin{array}{l}\text { GE } \\
\text { Dharmacon }\end{array}$ & & $\begin{array}{l}\text { M-019553- } \\
01-0005\end{array}$ \\
\hline $\begin{array}{l}\text { BCAR1 } \\
\text { siRNA Pool }\end{array}$ & $\begin{array}{l}\text { 5'-AAGCAGTTTGAACGACTGGAA-3' } \\
\text { 5'-CTGGATGGAGGACTATGACTA-3' } \\
\text { 5'-CAGCATCACGCGGCAGGGCAA-3' } \\
\text { 5'-CAACCTGACCACACTGACCAA-3' }\end{array}$ & Qiagen & & $\begin{array}{l}\text { SI02757741 } \\
\text { SI02757734 } \\
\text { SI04438280 } \\
\text { SI04438273 }\end{array}$ \\
\hline
\end{tabular}




\begin{tabular}{|c|c|c|c|c|}
\hline $\begin{array}{l}\text { BCAR3 } \\
\text { siRNA Pool }\end{array}$ & $\begin{array}{l}\text { 5'-CCGGAACTCTGGCGTCAACTA-3' } \\
\text { 5'-CCGAGCGGCCACTCTGAGTAA-3' } \\
\text { 5'-GCCCAACGAGTTTGAGTCAAA-3' } \\
\text { 5'-AAGGTATCAGTTATATGATAT-3' }\end{array}$ & Qiagen & & $\begin{array}{l}\text { SI03081603 } \\
\text { SI03080196 } \\
\text { SI00053102 } \\
\text { SI00053095 }\end{array}$ \\
\hline $\begin{array}{l}\text { BCAR3 } \\
\text { siRNA }\end{array}$ & 5'-GGUAACUACUGCUAAUGUUTT-3' & $\begin{array}{l}\text { Life } \\
\text { Technologies }\end{array}$ & $\begin{array}{l}\text { Targets } \\
\text { 3'UTR }\end{array}$ & AM16708 \\
\hline
\end{tabular}

\section{qPCR}

An RNeasy Plus Mini kit (Qiagen) was used to extract RNA and an iScript reverse transcription supermix (BioRad) was used to make cDNA. Control reactions lacked reverse transcriptase. cDNA abundance was measured using an iTaq Universal SYBR Green Supermix kit (BioRad). Samples were run on the QuantStudio 5 Real-Time PCR System.

\begin{tabular}{|l|l|}
\hline Primer & Sequence \\
\hline BCAR3 forward & 5' - AATCGCTTCTCCAAACAGAGC - 3' \\
\hline BCAR3 reverse & $5^{\prime}$ - ATTCACCGGCATGTTTCTGG - 3' \\
\hline Cul5 forward & $5^{\prime}$ - TTTTATGCGCCCGATTGTTTTG - 3' \\
\hline Cul5 reverse & $5^{\prime}-$ TTGCTGGGCCTTTATCATCCC - 3' \\
\hline GAPDH forward & $5^{\prime}-$ CAGCCTCAAGATCATCAGCA - 3' \\
\hline GAPDH reverse & $5^{\prime}-$ TGTGGTCATGAGTCCTTCCA - 3' \\
\hline
\end{tabular}

\section{Cell lysis and Immunoblotting}

Cells were washed three times in phosphate-buffered saline (PBS) before lysis. Cells were lysed in X-100 buffer (1\% Triton X-100, 150 mM NaCl, 10 mM HEPES pH 7.4, 2 mM EDTA, 50 $\mathrm{mM} \mathrm{NaF}$ ) or RIPA buffer (1\% Triton X-100, 1\% sodium deoxycholate, 0.1\% SDS, $20 \mathrm{mM}$ Tris$\mathrm{HCl} \mathrm{pH} \mathrm{7.4,} 150 \mathrm{mM} \mathrm{NaCl}, 5 \mathrm{mM}$ EDTA, 5 mM EGTA) with fresh protease and phosphatase inhibitors (10 $\mu \mathrm{g} / \mathrm{mL}$ Aprotinin, $1 \mathrm{mM}$ PMSF, $1 \mathrm{mM}$ sodium vanadate) added before use.

Lysates were adjusted to SDS sample buffer, heated to $95^{\circ} \mathrm{C}$, resolved by SDS-PAGE using $10 \%$ polyacrylamide/ $0.133 \%$ bis-acrylamide gels, and transferred onto nitrocellulose membrane. The membrane was blocked in Odyssey blocking buffer (TBS) (LI-COR Biosciences) with 5\% BSA for phosphotyrosine antibodies or $5 \%$ non-fat dry milk for all other antibodies. Following 
blocking, the membrane was probed with a primary antibody followed by IRDye 800CW goat anti-rabbit or 680RD goat anti-mouse conjugated secondary antibodies. Membranes were visualized using the Odyssey Infrared Imaging System (LI-COR Biosciences). Bands were quantified using ImageJ.

\section{DNA transfections and Immunoprecipitation}

HeLa cells were plated in 6-well plates the day before transfection such that cells were $50 \%$ confluent on the day of transfection. A mixture of DNA, Lipofectamine 2000 (Thermo Fisher Scientific) and Optimem (Invitrogen) was made according to manufacturer's protocol, added to the cells and removed after 5 hours.

Immunoprecipitation experiments were conducted 24-48 hours after transfection. For indicated experiments, cells were incubated with $1 \mathrm{mM}$ sodium pervanadate for 30 minutes. Cells were lysed on ice in X-100 buffer with fresh protease and phosphatase inhibitors (see above). Lysates were cleared by centrifugation for 10 minutes at 14,000 g. Lysates were rotated with 1 $\mu \mathrm{g}$ antibody at $4^{\circ} \mathrm{C}$ for 3 hours, after which Protein A/G plus agarose beads (Santa Cruz Biotechnology) were added for 1 hour at $4^{\circ} \mathrm{C}$. Beads were collected by centrifugation and washed three times with X-100 buffer. The beads were resuspended in SDS sample buffer, boiled, lightly mixed to release bound protein and centrifuged. Immunoprecipitation samples were resolved by SDS-PAGE using 10\% polyacrylamide gels and bound proteins detected by Western blotting as above. Samples of total cell lysate typically contained $5 \%$ of the protein used for immunoprecipitation.

\section{Cycloheximide chase}

Cells were grown to $80 \%$ confluency and treated with $25 \mu \mathrm{g} / \mathrm{mL}$ cycloheximide by adding it directly to the conditioned media on the cells. Cells were treated with cycloheximide for $0,2,4$, or 8 hours and lysed. Quantification of Western blots was done in ImageJ and BCAR3 protein levels were normalized to the loading control (GAPDH or vinculin).

\section{Scratch wound assay}

The desired proteins were knocked down using two siRNA transfections, as previously described. Cells were plated in ImageLock 96-well dishes (Essen BioScience) for the second siRNA transfection and transfection materials were scaled down proportional to dish sizes. Cells were plated at $30 \%$ confluence at the time of the second transfection. For migration assays 
where doxycycline (dox)-induction was required, the media was replaced with growth media containing dox (10 ng/mL except where noted) 6 hours after transfection and after two washes with PBS. For all migration assays, the confluent monolayers were placed in EGF-free assay media (with dox when required) 48 hours after the second transfection transfection. Monolayers were scratched using an Incucyte WoundMaker (Essen BioScience) 8 hours after being placed in assay media, the wells were washed with PBS three times to remove debris and cells were placed back in assay media (with dox when required). Scratch wounds were imaged once every 2 hours on an IncuCyte S3 and images were analyzed using the scratch wound function on the IncuCyte image analysis software. Overall migration was measured at 12 hours using the relative wound density calculated by the analysis software. Lamellipodium length was measured using the ruler in the IncuCyte image analysis software. Membrane ruffling was scored at 6 hours by counting the number of cells with ruffles relative to the total cell number. Ruffles were visualized as dark contrast at the front of the protrusion.

\section{Transwell migration and invasion assays}

Cells were grown in EGF-free assay media for 24 hours before the assay. Migration assays were performed in 24-well chemotaxis chamber with an $8 \mu \mathrm{m}$ pore size polyethylene terephthalate filter that separated the upper and lower wells (Thermo Fisher Scientific). Invasion assays were performed in 24-well Matrigel invasion chambers with an $8 \mu \mathrm{m}$ pore size polyethylene terephthalate filter coated in Matrigel matrix that separated the upper and lower wells (Thermo Fisher Scientific). In both assays, the lower wells were filled with MCF10A growth media. 80,000 cells were resuspended in EGF-free assay media and added to the top well. After 24 hours, cells on the top of the membrane were removed and the cells on the bottom of the membrane were fixed with methanol and stained with SybrSafe at 1:10,000 for 15 minutes. Membranes were rinsed, imaged and nuclei were counted.

\section{Immunofluorescence}

For experiments that required protein knockdown, cells were transfected with siRNA as previously described. On the day following the second siRNA transfection, cells were plated on 12-mm \#1.5 coverslips at 30\% confluency in 4-well $\left(1.9 \mathrm{~cm}^{2}\right)$ plates (with dox when required). Confluent monolayers were transferred to assay media and incubated overnight before scratching with a P200 pipette tip. To detect the SNAP tag, JaneliaFluor cpJF549 SNAP-ligand (Lavis Lab, Janelia Farms) (Grimm et al., 2015) was added to the cells at $100 \mathrm{nM} 4$ hours after forming the wounds. Cells were incubated for 1 hour with the SNAP-ligand, washed three times 
with PBS and placed in fresh, ligand-free assay media for 1 hour to remove unreacted SNAPligand. Cells were fixed and permeabilized a total of 6 hours after the start of migration.

Fixation and immunostaining was done at room temperature. Cells were washed with PBS, fixed and permeabilized with $0.1 \%$ Triton X-100, $4 \%$ paraformaldehyde (PFA) in PBS for 2 minutes, and further fixed with 4\% PFA/PBS for 15 minutes. Cells were blocked with $2 \%$ BSA, $5 \%$ normal goat serum in PBS for 30 minutes or overnight at $4{ }^{\circ} \mathrm{C}$. Primary antibodies were diluted in block solution (typically 1:200 dilution) and added for 3 hours. Coverslips were washed three times with PBS. AlexaFluor-labeled secondary antibodies, diluted 1:1000 in PBS, were added for 1 hour. Coverslips were washed three times with PBS, mounted in Prolong Glass Antifade Mountant and left to cure overnight in the dark before imaging or storing in the cold.

\section{Imaging and image quantification}

Coverslips were imaged using $63 x, 1.40$ NA or 100x, 1.40 NA oil objectives on a Leica SP8 confocal microscope and deconvolved using Leica LAS acquisition software. In order to ensure unbiased data collection, 8-14 cells along the leading edge of the wound were imaged in the paxillin channel before imaging channels showing other antigen(s) of interest. The same scale and image settings were used for all conditions within an experiment. The number of cells and biological replicates is provided in each figure legend.

Image quantification was done in ImageJ. A line was drawn $\sim 6 \mu \mathrm{m}$ from the front of the migrating cells, as described (Teckchandani et al., 2016), to isolate the leading edge. Using the threshold tool on ImageJ, paxillin-containing adhesions were identified and mean intensity of SNAP or other antigens (pY-Cas, Cas, pY397-FAK, pY-861-FAK and paxillin) was measured. The relative abundance of each antigen in adhesions was calculated by dividing the mean antigen intensity by the mean intensity of paxillin. Because expression of SNAP-V5-BCAR3 varied slightly cell by cell, we corrected for expression level as follows. SNAP intensity was measured in the leading edge adhesions $\left(\mathrm{SNAP}_{\mathrm{ad}}\right)$, at the rear of the cell (SNAPrear) and in non-

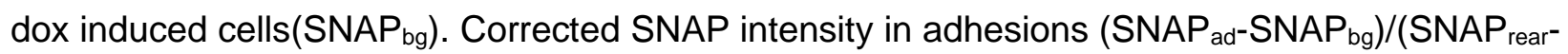
$\mathrm{SNAP}_{\mathrm{bg}}$ ) was divided by the mean paxillin intensity.

\section{Acknowledgements}

We are most grateful to Forest White for advice on quantitative phosphotyrosine proteomics and Amanda Del Rosario of the Koch Institute Proteomics Core for running the analysis. Julio 
Vazquez, Dave McDonald, Lena Schroeder and Peng Guo of the FHCRC Cellular Imaging Shared Resource provided outstanding assistance with microscopy. We thank Patrick Paddison, Anne-Claude Gingras and Susumu Antoku for plasmids and Luke Lavis for Janelia Fluors. Laura Arguedas-Jiminez provided excellent technical assistance. We are grateful to Saurav Kumar and Dayoung Kim for discussion and helpful comments on the paper.

E.S. was supported in part by Predoctoral Institutional Training Program T32 GM007270 to the University of Washington. This work was supported by research grant R01 GM109463 from the US Public Health Service and by discretionary funds from the Fred Hutchinson Cancer Research Center. The FHCRC Flow Cytometry and Cellular Imaging Shared Resources are supported by P30 CA015704. The Koch Institute Proteomics Core is supported by P30 CA14051. 
Bachir AI, Horwitz AR, Nelson WJ, Bianchini JM. 2017. Actin-based adhesion modules mediate cell interactions with the extracellular matrix and neighboring cells. Cold Spring Harb Perspect Bio/ 9. doi: 10.1101/cshperspect.a023234.

Baron U, Gossen M, Bujard H. 1997. Tetracycline-controlled transcription in eukaryotes: novel transactivators with graded transactivation potential. Nucleic Acids Res 25:2723-9.

Bayle J, Letard S, Frank R, Dubreuil P, De Sepulveda P. 2004. Suppressor of cytokine signaling 6 associates with KIT and regulates KIT receptor signaling. J Biol Chem 279:12249-59. doi: 10.1074/jbc.M313381200.

Boettner B, Van Aelst L. 2009. Control of cell adhesion dynamics by Rap1 signaling. Curr Opin Cell Biol 21:684-93.

Branis J, Pataki C, Sporrer M, Gerum RC, Mainka A, Cermak V, Goldmann WH, Fabry B, Brabek J, Rosel D. 2017. The role of focal adhesion anchoring domains of CAS in mechanotransduction. Sci Rep 7:46233. doi: 10.1038/srep46233.

Burridge K, Turner CE, Romer LH. 1992. Tyrosine phosphorylation of paxillin and pp125FAK accompanies cell adhesion to extracellular matrix: a role in cytoskeletal assembly. $J$ Cell Biol 119:893-903.

Cai D, Clayton LK, Smolyar A, Lerner A. 1999. AND-34, a novel p130Cas-binding thymic stromal cell protein regulated by adhesion and inflammatory cytokines. J Immunol 163:2104-12.

Cai D, lyer A, Felekkis KN, Near RI, Luo Z, Chernoff J, Albanese C, Pestell RG, Lerner A. 2003. AND-34/BCAR3, a GDP exchange factor whose overexpression confers antiestrogen resistance, activates Rac, PAK1, and the cyclin D1 promoter. Cancer Res 63:6802-8.

Case LB, Waterman CM. 2015. Integration of actin dynamics and cell adhesion by a threedimensional, mechanosensitive molecular clutch. Nat Cell Biol. doi: 10.1038/ncb3191.

Cheresh DA, Leng J, Klemke RL. 1999. Regulation of cell contraction and membrane ruffling by distinct signals in migratory cells. J Cell Biol 146:1107-16.

Cross AM, Wilson AL, Guerrero MS, Thomas KS, Bachir AI, Kubow KE, Horwitz AR, Bouton $\mathrm{AH}$. 2016. Breast cancer antiestrogen resistance 3-p130(Cas) interactions promote adhesion disassembly and invasion in breast cancer cells. Oncogene 35:5850-5859. doi: 10.1038/onc.2016.123.

Curran TG, Bryson BD, Reigelhaupt M, Johnson H, White FM. 2013. Computer aided manual validation of mass spectrometry-based proteomic data. Methods 61:219-26. doi: 10.1016/j.ymeth.2013.03.004.

Defilippi P, Di Stefano P, Cabodi S. 2006. p130Cas: a versatile scaffold in signaling networks. Trends Cell Biol 16:257-63.

del Rio A, Perez-Jimenez R, Liu R, Roca-Cusachs P, Fernandez JM, Sheetz MP. 2009. Stretching single talin rod molecules activates vinculin binding. Science 323:638-41. doi: 10.1126/science.1162912.

DeMali KA, Barlow CA, Burridge K. 2002. Recruitment of the Arp2/3 complex to vinculin: coupling membrane protrusion to matrix adhesion. J Cell Biol 159:881-91.

Donato DM, Ryzhova LM, Meenderink LM, Kaverina I, Hanks SK. 2010. Dynamics and mechanism of p130Cas localization to focal adhesions. J Biol Chem 285:20769-79. doi: 10.1074/jbc.M109.091207.

Feng L, Cooper JA. 2009. Dual functions of Dab1 during brain development. Mol Cell Biol 29:324-32.

Fonseca PM, Shin NY, Brabek J, Ryzhova L, Wu J, Hanks SK. 2004. Regulation and localization of CAS substrate domain tyrosine phosphorylation. Cell Signal 16:621-9.

Galbraith CG, Yamada KM, Sheetz MP. 2002. The relationship between force and focal complex development. J Cell Biol 159:695-705. doi: 10.1083/jcb.200204153. 
Goldberg GS, Alexander DB, Pellicena P, Zhang ZY, Tsuda H, Miller WT. 2003. Src phosphorylates Cas on tyrosine 253 to promote migration of transformed cells. J Biol Chem 278:46533-40.

Grimm JB, English BP, Chen J, Slaughter JP, Zhang Z, Revyakin A, Patel R, Macklin JJ, Normanno D, Singer RH, Lionnet T, Lavis LD. 2015. A general method to improve fluorophores for live-cell and single-molecule microscopy. Nat Methods 12:244-50, $3 \mathrm{p}$ following 250. doi: 10.1038/nmeth.3256.

Guo J, Canaff L, Rajadurai CV, Fils-Aime N, Tian J, Dai M, Korah J, Villatoro M, Park M, Ali S, Lebrun JJ. 2014. Breast cancer anti-estrogen resistance 3 inhibits transforming growth factor beta/Smad signaling and associates with favorable breast cancer disease outcomes. Breast Cancer Res 16:476. doi: 10.1186/s13058-014-0476-9.

Harte MT, Hildebrand JD, Burnham MR, Bouton AH, Parsons JT. 1996. p130Cas, a substrate associated with v-Src and v-Crk, localizes to focal adhesions and binds to focal adhesion kinase. J Biol Chem 271:13649-55. doi: 10.1074/jbc.271.23.13649.

Hasegawa H, Kiyokawa E, Tanaka S, Nagashima K, Gotoh N, Shibuya M, Kurata T, Matsuda M. 1996. DOCK180, a major CRK-binding protein, alters cell morphology upon translocation to the cell membrane. Mol Cell Biol 16:1770-6.

Honda H, Nakamoto T, Sakai R, Hirai H. 1999. p130(Cas), an assembling molecule of actin filaments, promotes cell movement, cell migration, and cell spreading in fibroblasts. Biochem Biophys Res Commun 262:25-30.

Hornbeck PV, Kornhauser JM, Latham V, Murray B, Nandhikonda V, Nord A, Skrzypek E, Wheeler T, Zhang B, Gnad F. 2019. 15 years of PhosphoSitePlus(R): integrating posttranslationally modified sites, disease variants and isoforms. Nucleic Acids Res 47:D433-D441. doi: 10.1093/nar/gky1159.

Hotta K, Ranganathan S, Liu R, Wu F, Machiyama H, Gao R, Hirata H, Soni N, Ohe T, Hogue CW, Madhusudhan MS, Sawada Y. 2014. Biophysical properties of intrinsically disordered p130Cas substrate domain--implication in mechanosensing. PLoS Comput Biol 10:e1003532. doi: 10.1371/journal.pcbi.1003532.

Huang MM, Lipfert L, Cunningham M, Brugge JS, Ginsberg MH, Shattil SJ. 1993. Adhesive ligand binding to integrin alpha Ilb beta 3 stimulates tyrosine phosphorylation of novel protein substrates before phosphorylation of pp125FAK. J Cell Biol 122:473-83.

Jaber Chehayeb R, Boggon TJ. 2020. SH2 Domain Binding: Diverse FLVRs of Partnership. Front Endocrinol (Lausanne) 11:575220. doi: 10.3389/fendo.2020.575220.

Janostiak R, Brabek J, Auernheimer V, Tatarova Z, Lautscham LA, Dey T, Gemperle J, Merkel R, Goldmann WH, Fabry B, Rosel D. 2014. CAS directly interacts with vinculin to control mechanosensing and focal adhesion dynamics. Cell Mol Life Sci 71:727-44. doi: 10.1007/s00018-013-1450-x.

Kazi JU, Sun J, Phung B, Zadjali F, Flores-Morales A, Ronnstrand L. 2012. Suppressor of cytokine signaling 6 (SOCS6) negatively regulates Flt3 signal transduction through direct binding to phosphorylated tyrosines 591 and 919 of Flt3. J Biol Chem 287:36509-17. doi: 10.1074/jbc.M112.376111.

Keppler A, Gendreizig S, Gronemeyer T, Pick H, Vogel H, Johnsson K. 2003. A general method for the covalent labeling of fusion proteins with small molecules in vivo. Nat Biotechnol 21:86-9. doi: 10.1038/nbt765.

Kiyokawa E, Hashimoto Y, Kobayashi S, Sugimura H, Kurata T, Matsuda M. 1998. Activation of Rac1 by a Crk SH3-binding protein, DOCK180. Genes Dev 12:3331-6.

Klemke RL, Leng J, Molander R, Brooks PC, Vuori K, Cheresh DA. 1998. CAS/Crk coupling serves as a "molecular switch" for induction of cell migration. J Cell Biol 140:961-72.

Kostic A, Sheetz MP. 2006. Fibronectin rigidity response through Fyn and p130Cas recruitment to the leading edge. Mol Biol Cell 17:2684-95. 
Krebs DL, Uren RT, Metcalf D, Rakar S, Zhang JG, Starr R, De Souza DP, Hanzinikolas K, Eyles J, Connolly LM, Simpson RJ, Nicola NA, Nicholson SE, Baca M, Hilton DJ, Alexander WS. 2002. SOCS-6 binds to insulin receptor substrate 4, and mice lacking the SOCS-6 gene exhibit mild growth retardation. Mol Cell Biol 22:4567-78.

Legate KR, Wickstrom SA, Fassler R. 2009. Genetic and cell biological analysis of integrin outside-in signaling. Genes Dev 23:397-418. doi: 10.1101/gad.1758709.

Marengere LE, Pawson T. 1994. Structure and function of SH2 domains. J Cell Sci Suppl 18:97-104. doi: 10.1242/jcs.1994.supplement_18.14.

Mitra SK, Schlaepfer DD. 2006. Integrin-regulated FAK-Src signaling in normal and cancer cells. Curr Opin Cell Biol 18:516-23.

Miyamoto S, Teramoto H, Coso OA, Gutkind JS, Burbelo PD, Akiyama SK, Yamada KM. 1995. Integrin function: molecular hierarchies of cytoskeletal and signaling molecules. J Cell Biol 131:791-805. doi: 10.1083/jcb.131.3.791.

Nakamoto T, Sakai R, Honda H, Ogawa S, Ueno H, Suzuki T, Aizawa S, Yazaki Y, Hirai H. 1997. Requirements for localization of p130cas to focal adhesions. Mol Cell Biol 17:3884-97.

Nojima Y, Morino N, Mimura T, Hamasaki K, Furuya H, Sakai R, Sato T, Tachibana K, Morimoto C, Yazaki Y, Hirai H. 1995. Integrin-mediated cell adhesion promotes tyrosine phosphorylation of p130Cas, a Src homology 3-containing molecule having multiple Src homology 2-binding motifs. J Biol Chem 270:15398-402.

Oh MJ, van Agthoven T, Choi JE, Jeong YJ, Chung YH, Kim CM, Jhun BH. 2008. BCAR3 regulates EGF-induced DNA synthesis in normal human breast MCF-12A cells. Biochem Biophys Res Commun 375:430-4. doi: 10.1016/j.bbrc.2008.08.040.

Oh MJ, Yi SJ, Kim HS, Kim JH, Jeong YH, van Agthoven T, Jhun BH. 2013. Functional roles of BCAR3 in the signaling pathways of insulin leading to DNA synthesis, membrane ruffling and GLUT4 translocation. Biochem Biophys Res Commun 441:911-6. doi: 10.1016/j.bbrc.2013.10.161.

Okumura F, Joo-Okumura A, Nakatsukasa K, Kamura T. 2016. The role of cullin 5-containing ubiquitin ligases. Cell Div 11:1. doi: 10.1186/s13008-016-0016-3.

Partridge MA, Marcantonio EE. 2006. Initiation of attachment and generation of mature focal adhesions by integrin-containing filopodia in cell spreading. Mol Biol Cell 17:4237-48.

Pasapera AM, Schneider IC, Rericha E, Schlaepfer DD, Waterman CM. 2010. Myosin II activity regulates vinculin recruitment to focal adhesions through FAK-mediated paxillin phosphorylation. J Cell Biol 188:877-90. doi: 10.1083/jcb.200906012.

Polte TR, Hanks SK. 1995. Interaction between focal adhesion kinase and Crk-associated kinase substrate p130cas. Proceedings of the National Academy of Sciences of the United States of America 92:10678-10682.

Ponniah S, Wang DZ, Lim KL, Pallen CJ. 1999. Targeted disruption of the tyrosine phosphatase PTPalpha leads to constitutive downregulation of the kinases Src and Fyn. Curr Biol 9:535-8.

Pratt SJ, Epple H, Ward M, Feng Y, Braga VM, Longmore GD. 2005. The LIM protein Ajuba influences p130Cas localization and Rac1 activity during cell migration. J Cell Biol 168:813-24.

Puklin-Faucher E, Sheetz MP. 2009. The mechanical integrin cycle. J Cell Sci 122:179-86. doi: $10.1242 / j c s .042127$.

Ren XD, Kiosses WB, Sieg DJ, Otey CA, Schlaepfer DD, Schwartz MA. 2000. Focal adhesion kinase suppresses Rho activity to promote focal adhesion turnover. J Cell Sci 113 ( Pt 20):3673-8.

Ridley AJ. 2001. Rho GTPases and cell migration. J Cell Sci 114:2713-22.

Ridley AJ, Paterson HF, Johnston CL, Diekmann D, Hall A. 1992. The small GTP-binding protein rac regulates growth factor-induced membrane ruffling. Cell 70:401-410. 
Riggins RB, Quilliam LA, Bouton AH. 2003. Synergistic promotion of c-Src activation and cell migration by Cas and AND-34/BCAR3. J Biol Chem 278:28264-73. doi: 10.1074/jbc.M303535200.

Roselli S, Wallez Y, Wang L, Vervoort V, Pasquale EB. 2010. The SH2 domain protein Shep1 regulates the in vivo signaling function of the scaffolding protein Cas. Cell Signal 22:1745-52. doi: 10.1016/j.cellsig.2010.06.015.

Rottner K, Hall A, Small JV. 1999. Interplay between Rac and Rho in the control of substrate contact dynamics. Curr Biol 9:640-8.

Sakai R, Iwamatsu A, Hirano N, Ogawa S, Tantaka T, Mano H, Yazaki Y, Hirai H. 1994. A novel signaling molecule, p130, forms stable complexes in vivo with v-Crk and v-Src in a tyrosine phosphorylation-dependent manner. EMBO Journal 13:3748-3756.

Sakai R, Nakamoto T, Ozawa K, Aizawa S, Hirai H. 1997. Characterization of the kinase activity essential for tyrosine phosphorylation of p130Cas in fibroblasts. Oncogene 14:1419-26. doi: $10.1038 /$ sj.onc. 1200954.

Sanders MA, Basson MD. 2005. p130cas but not paxillin is essential for Caco-2 intestinal epithelial cell spreading and migration on collagen IV. J Biol Chem 280:23516-22.

Sawada Y, Tamada M, Dubin-Thaler BJ, Cherniavskaya O, Sakai R, Tanaka S, Sheetz MP. 2006. Force sensing by mechanical extension of the Src family kinase substrate p130Cas. Cell 127:1015-26.

Schaller MD, Borgman CA, Cobb BS, Vines RR, Reynolds AB, Parsons JT. 1992. pp125FAK a structurally distinctive protein-tyrosine kinase associated with focal adhesions. Proc Natl Acad Sci U S A 89:5192-6. doi: 10.1073/pnas.89.11.5192.

Schaller MD, Parsons JT. 1995. pp125FAK-dependent tyrosine phosphorylation of paxillin creates a high-affinity binding site for Crk. Molecular and Cellular Biology 15:2635-2645.

Schrecengost RS, Riggins RB, Thomas KS, Guerrero MS, Bouton AH. 2007. Breast cancer antiestrogen resistance-3 expression regulates breast cancer cell migration through promotion of $130 \mathrm{Cas}$ membrane localization and membrane ruffling. Cancer Res 67:6174-82. doi: 10.1158/0008-5472.CAN-06-3455.

Schuh NR, Guerrero MS, Schrecengost RS, Bouton AH. 2010. BCAR3 regulates Src/p130 Cas association, Src kinase activity, and breast cancer adhesion signaling. J Biol Chem 285:2309-17. doi: 10.1074/jbc.M109.046631.

Sharma A, Mayer BJ. 2008. Phosphorylation of p130Cas initiates Rac activation and membrane ruffling. BMC Cell Biol 9:50.

Simo S, Cooper JA. 2013. Rbx2 regulates neuronal migration through different cullin 5-RING ligase adaptors. Dev Cell 27:399-411. doi: 10.1016/j.devcel.2013.09.022.

Songyang Z, Shoelson SE, Chaudhuri M, Gish G, Pawson T, Haser WG, King F, Roberts T, Ratnofsky S, Lechleider RJ, et al. 1993. SH2 domains recognize specific phosphopeptide sequences. Cell 72:767-78. doi: 10.1016/0092-8674(93)90404-e.

Stradal TE, Rottner K, Disanza A, Confalonieri S, Innocenti M, Scita G. 2004. Regulation of actin dynamics by WASP and WAVE family proteins. Trends Cell Biol 14:303-11.

Stutchbury B, Atherton P, Tsang R, Wang DY, Ballestrem C. 2017. Distinct focal adhesion protein modules control different aspects of mechanotransduction. J Cell Sci 130:16121624. doi: $10.1242 / j c s .195362$.

Su J, Muranjan M, Sap J. 1999. Receptor protein tyrosine phosphatase alpha activates Srcfamily kinases and controls integrin-mediated responses in fibroblasts. Curr Biol 9:50511.

Sun G, Cheng SY, Chen M, Lim CJ, Pallen CJ. 2012. Protein tyrosine phosphatase alpha phosphotyrosyl-789 binds BCAR3 to position Cas for activation at integrin-mediated focal adhesions. Mol Cell Biol 32:3776-89. doi: 10.1128/MCB.00214-12. 
Tadokoro S, Shattil SJ, Eto K, Tai V, Liddington RC, de Pereda JM, Ginsberg MH, Calderwood DA. 2003. Talin binding to integrin beta tails: a final common step in integrin activation. Science 302:103-6.

Tamada M, Sheetz MP, Sawada Y. 2004. Activation of a signaling cascade by cytoskeleton stretch. Dev Cell 7:709-18.

Tanaka S, Morishita T, Hashimoto Y, Hattori S, Nakamura S, Shibuya M, Matuoka K, Takenawa T, Kurata T, Nagashima K, Matsuda M. 1994. C3G, a guanine nucleotide-releasing protein expressed ubiquitously, binds to the Src homology 3 domains of CRK and GRB2/ASH proteins. Proc Natl Acad Sci U S A 91:3443-7.

Teckchandani A, Cooper JA. 2016. The ubiquitin-proteasome system regulates focal adhesions at the leading edge of migrating cells. Elife 5. doi: 10.7554/eLife.17440.

Teckchandani A, Laszlo GS, Simo S, Shah K, Pilling C, Strait AA, Cooper JA. 2014. Cullin 5 destabilizes Cas to inhibit Src-dependent cell transformation. J Cell Sci 127:509-20. doi: 10.1242/jcs. 127829.

Tikhmyanova N, Little JL, Golemis EA. 2010. CAS proteins in normal and pathological cell growth control. Cell Mol Life Sci 67:1025-48. doi: 10.1007/s00018-009-0213-1.

Trepat X, Chen Z, Jacobson K. 2012. Cell migration. Compr Physiol 2:2369-92. doi: 10.1002/cphy.c110012.

van Agthoven T, van Agthoven TL, Dekker A, van der Spek PJ, Vreede L, Dorssers LC. 1998. Identification of BCAR3 by a random search for genes involved in antiestrogen resistance of human breast cancer cells. EMBO J 17:2799-808. doi: 10.1093/emboj/17.10.2799.

von Wichert G, Jiang G, Kostic A, De Vos K, Sap J, Sheetz MP. 2003. RPTP-alpha acts as a transducer of mechanical force on alphav/beta3-integrin-cytoskeleton linkages. J Cell Biol 161:143-53. doi: 10.1083/jcb.200211061.

Vuori K, Hirai H, Aizawa S, Ruoslahti E. 1996. Induction of p130cas signaling complex formation upon integrin-mediated cell adhesion: a role for Src family kinases. Mol Cell Biol 16:2606-13.

Vuori K, Ruoslahti E. 1995. Tyrosine phosphorylation of p130Cas and cortactin accompanies integrin-mediated cell adhesion to extracellular matrix. J Biol Chem 270:22259-62. doi: 10.1074/jbc.270.38.22259.

Wallez Y, Mace PD, Pasquale EB, Riedl SJ. 2012. NSP-CAS Protein Complexes: Emerging Signaling Modules in Cancer. Genes Cancer 3:382-93. doi: 10.1177/1947601912460050.

Wallez Y, Riedl SJ, Pasquale EB. 2014. Association of the breast cancer antiestrogen resistance protein 1 (BCAR1) and BCAR3 scaffolding proteins in cell signaling and antiestrogen resistance. J Biol Chem 289:10431-44. doi: 10.1074/jbc.M113.541839.

Webb DJ, Donais K, Whitmore LA, Thomas SM, Turner CE, Parsons JT, Horwitz AF. 2004. FAK-Src signalling through paxillin, ERK and MLCK regulates adhesion disassembly. Nat Cell Biol 6:154-61.

Wilson AL, Schrecengost RS, Guerrero MS, Thomas KS, Bouton AH. 2013. Breast cancer antiestrogen resistance 3 (BCAR3) promotes cell motility by regulating actin cytoskeletal and adhesion remodeling in invasive breast cancer cells. PLoS One 8:e65678. doi: 10.1371/journal.pone.0065678.

Wu X, Suetsugu S, Cooper LA, Takenawa T, Guan JL. 2004. Focal adhesion kinase regulation of N-WASP subcellular localization and function. J Biol Chem 279:9565-76. doi: 10.1074/jbc.M310739200.

Yang X, Boehm JS, Yang X, Salehi-Ashtiani K, Hao T, Shen Y, Lubonja R, Thomas SR, Alkan O, Bhimdi T, Green TM, Johannessen CM, Silver SJ, Nguyen C, Murray RR, Hieronymus H, Balcha D, Fan C, Lin C, Ghamsari L, Vidal M, Hahn WC, Hill DE, Root 
DE. 2011. A public genome-scale lentiviral expression library of human ORFs. Nat Methods 8:659-61. doi: 10.1038/nmeth.1638.

Yi J, Kloeker S, Jensen CC, Bockholt S, Honda H, Hirai H, Beckerle MC. 2002. Members of the Zyxin family of LIM proteins interact with members of the p130Cas family of signal transducers. J Biol Chem 277:9580-9. doi: 10.1074/jbc.M106922200.

Zadjali F, Pike AC, Vesterlund M, Sun J, Wu C, Li SS, Ronnstrand L, Knapp S, Bullock AN, Flores-Morales A. 2011. Structural basis for C-KIT inhibition by the suppressor of cytokine signaling 6 (SOCS6) ubiquitin ligase. J Biol Chem 286:480-90.

Zaidel-Bar R, Milo R, Kam Z, Geiger B. 2007. A paxillin tyrosine phosphorylation switch regulates the assembly and form of cell-matrix adhesions. J Cell Sci 120:137-48. doi: $10.1242 / j c s .03314$.

Zhang W, Lin Y, Liu X, He X, Zhang Y, Fu W, Yang Z, Yang P, Wang J, Hu K, Zhang X, Liu W, Yuan $X$, Jing $H$. 2018. Prediction and prognostic significance of BCAR3 expression in patients with multiple myeloma. J Transl Med 16:363. doi: 10.1186/s12967-018-1728-8.

Zhang X, Moore SW, Iskratsch T, Sheetz MP. 2014. N-WASP-directed actin polymerization activates Cas phosphorylation and lamellipodium spreading. J Cell Sci 127:1394-405. doi: 10.1242/jcs.134692.

Zhang Y, Wolf-Yadlin A, Ross PL, Pappin DJ, Rush J, Lauffenburger DA, White FM. 2005. Time-resolved mass spectrometry of tyrosine phosphorylation sites in the epidermal growth factor receptor signaling network reveals dynamic modules. Mol Cell Proteomics 4:1240-50.

Zhang Y, Wolf-Yadlin A, White FM. 2007. Quantitative proteomic analysis of phosphotyrosinemediated cellular signaling networks. Methods Mol Biol 359:203-12. doi: 10.1007/978-159745-255-7_14.

Zhao Z, Tan SH, Machiyama H, Kawauchi K, Araki K, Hirata H, Sawada Y. 2016. Association between tensin 1 and $\mathrm{p} 130 \mathrm{Cas}$ at focal adhesions links actin inward flux to cell migration. Biol Open 5:499-506. doi: 10.1242/bio.016428.

Zheng XM, Resnick RJ, Shalloway D. 2000. A phosphotyrosine displacement mechanism for activation of Src by PTPalpha. Embo J 19:964-78. 


\section{Figure 1}

a

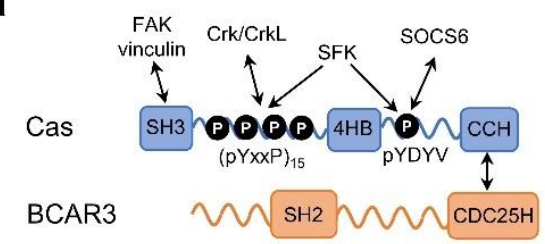

b

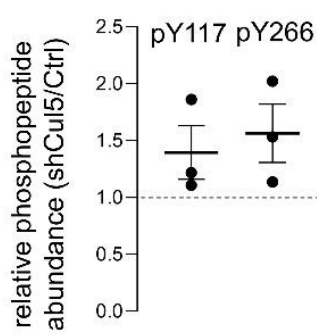

C

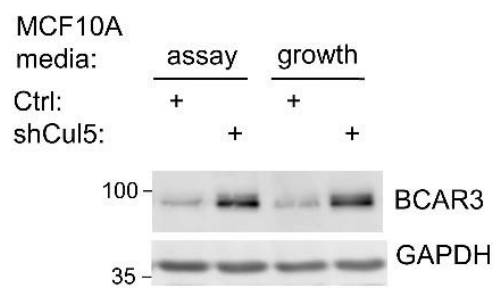

d

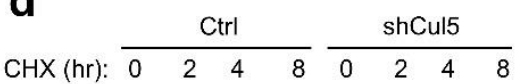
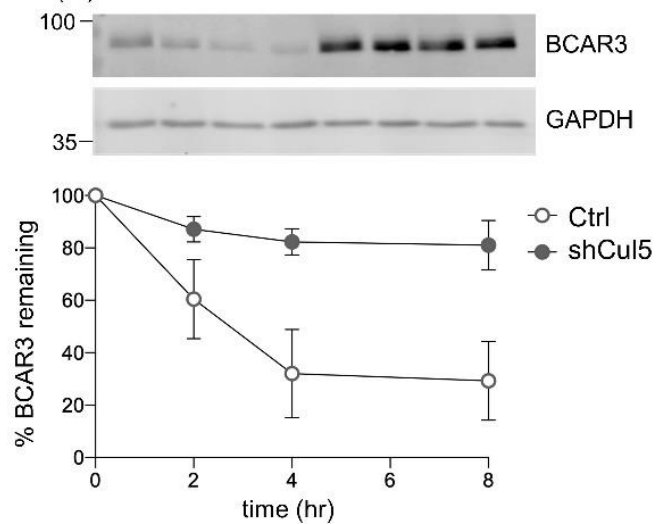

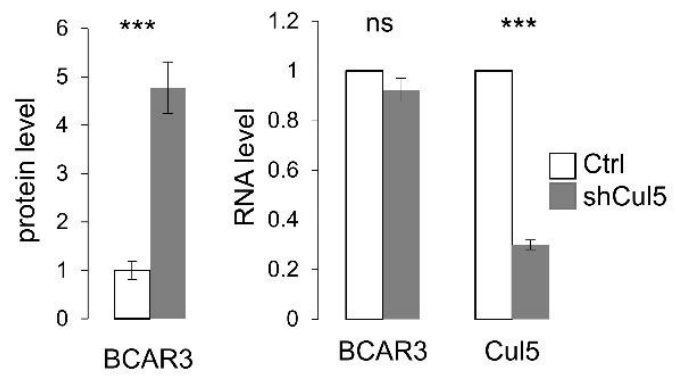

e
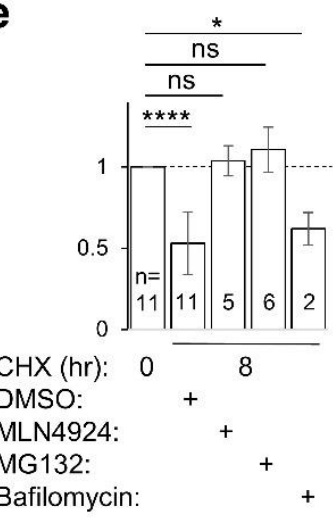

Figure 1. CRL5 regulates BCAR3 protein turnover. (a) Cas and BCAR3 structures. (b) Ratio of BCAR3 pY117 and pY266 phosphopeptide abundance in Cul5-deficient (shCul5) relative to control (Ctrl) MCF10A cells. $n=3$ biological replicates. (c) BCAR3 protein and RNA levels in Ctrl and shCul5 cells. Representative immunoblot of cells cultured in assay or growth media (see Methods). Quantification of BCAR3 immunoblots and RNA analysis by qPCR, both normalized to GAPDH. Mean \pm SD ; $=3$ biological replicates. ${ }^{* * *} \mathrm{p}<0.001$ (t-test). (d) BCAR3 degradation. Control and Cul5-deficient cells were treated with cycloheximide $(\mathrm{CHX})$ for various times. Representative immunoblot and quantification. Mean ${ }_{ \pm}$SEM ; $n=3$ biological replicates. (e) Proteasome-dependent BCAR3 degradation. MCF10A cells were treated for 8 hours with CHX and either MLN4924 (cullin neddylation inhibitor), MG132 (proteasome inhibitor) or bafilomycin A1 (lysosome inhibitor). Mean \pm SD; the number of biological replicates is noted on the graph. ${ }^{*} p<0.05$; ${ }^{* \star * *} \mathrm{p}<0.0001$ (One-way ANOVA). 
Figure 1 - figure supplement 1

\begin{tabular}{|c|c|c|c|c|c|c|c|}
\hline \multirow[t]{2}{*}{ Protein } & \multirow[t]{2}{*}{ Position } & \multirow[t]{2}{*}{ Uniprot } & \multirow[t]{2}{*}{ Sequence } & \multicolumn{2}{|c|}{ Experiment 1} & \multicolumn{2}{|c|}{ Experiment 2} \\
\hline & & & & Fold ${ }^{a}$ & $\mathrm{p}^{\mathrm{b}}$ & Fold ${ }^{a}$ & $p^{b}$ \\
\hline KRT6A & Y62 & Q92625 & sLyGLGGSk & 3.21 & 0.012 & 1.85 & 0.011 \\
\hline ABL1 & Y393 & P00519 & IMTGDTyTAHAGAk & 2.90 & 0.010 & 1.77 & 0.001 \\
\hline ANKS1A & Y455 & Q92625 & eEDEHPyELLLTAETK & 2.58 & 0.004 & 1.41 & 0.009 \\
\hline ARHGAP35 & Y1105 & Q9NRY4 & nEEENIYsVPHDSTQGk & 2.49 & 0.008 & 1.67 & 0.005 \\
\hline RIN1 & Y36 & Q13671 & ekPAQDPLyDVPNASGGQAGGPQRPGR & 2.02 & 0.018 & 1.45 & 0.018 \\
\hline BCAR3 & Y117 & 075815 & dPHLLDPTVEyVk & 1.96 & 0.011 & 1.34 & 0.049 \\
\hline MPZL1 & Y263 & 095297 & sESVVyADIR & 1.90 & 0.026 & 1.54 & 0.027 \\
\hline BCAR3 & Y266 & 075815 & cLEEHyGTSPGQAR & 1.81 & 0.000 & 1.50 & 0.012 \\
\hline BCAR1 & Y128 & P56945 & aQQGLyQVPGPSPQFQSPPAk & 1.80 & 0.003 & 1.28 & 0.036 \\
\hline SGK223 & Y413 & Q86YV5 & eATQPEPIyAESTk & 1.74 & 0.024 & 1.26 & 0.032 \\
\hline ENO1 & Y44 & P06733 & aAVPSGASTGIyEALELR & 1.64 & 0.004 & 1.18 & 0.032 \\
\hline ITGB4 & Y1207 & P16144 & vcAYGAQGEGPySSLVScR & 1.59 & 0.010 & 1.19 & 0.043 \\
\hline ANXA2 & Y30 & A6NMY6 & ayTNFDAER & 1.58 & 0.018 & 1.31 & 0.014 \\
\hline IGF1R & Y1165 & P08069 & dIYETDyYR & 1.53 & 0.030 & 1.69 & 0.001 \\
\hline PTPRA & Y798 & P18433 & vVQEYIDAFSDyANFk & 1.50 & 0.006 & 1.23 & 0.019 \\
\hline TLN1 & Y26 & Q9Y480 & tMQFEPSTMVyDAcR & 1.22 & 0.022 & 1.25 & 0.014 \\
\hline
\end{tabular}

Figure 1 - figure supplement 1. Phosphotyrosine peptides increased in Cul5-deficient cells. Protein names, tyrosine positions, Uniprot accession numbers, peptide sequences, and quantification of phosphotyrosine peptides that were significantly increased in two independent experiments, each performed in triplicate, comparing Cul5deficient and control MCF10A cells. In Experiment 1, the triplicate samples were obtained from cells starved for EGF for 0, 24 or 72 hours. In Experiment 2, the triplicate samples were all from unstarved cells. ${ }^{a}$ Ratio shCul5/Ctrl. ${ }^{b} \mathrm{p}$ value, t-test (2-tailed, paired); $n=3$. 


\section{Figure 2}

a

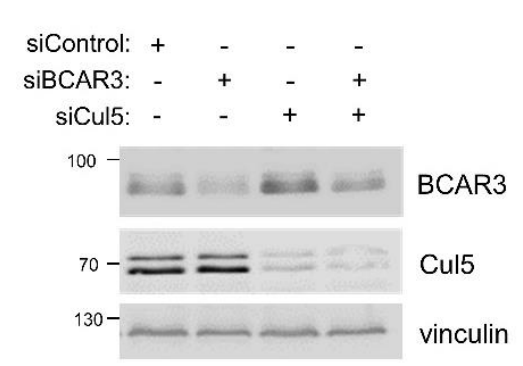

b

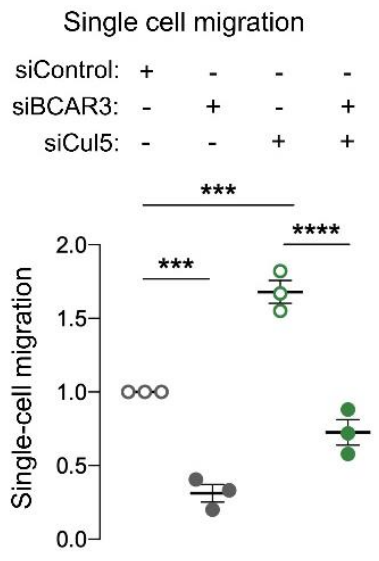

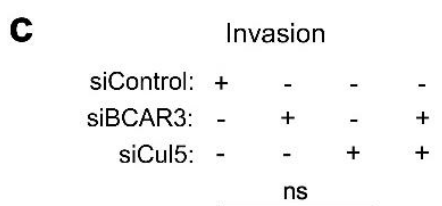

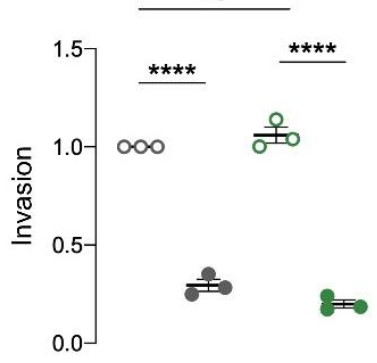

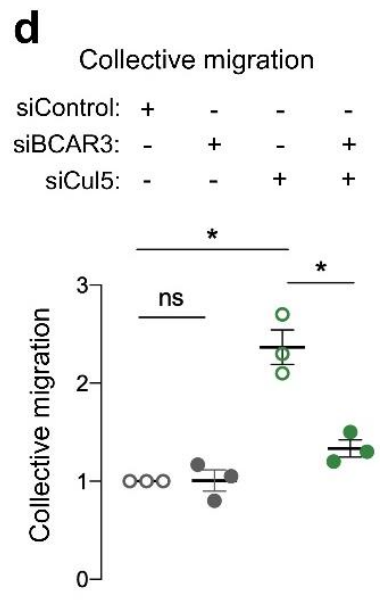

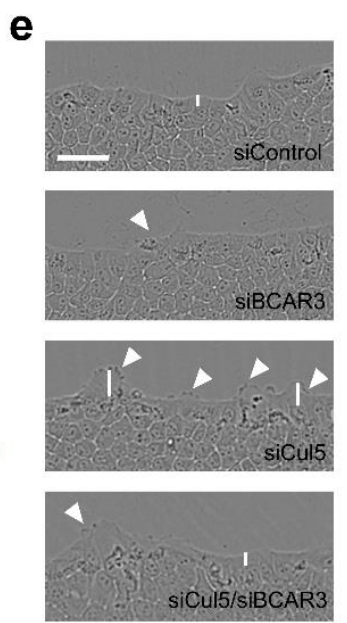

$\mathbf{f}$

g
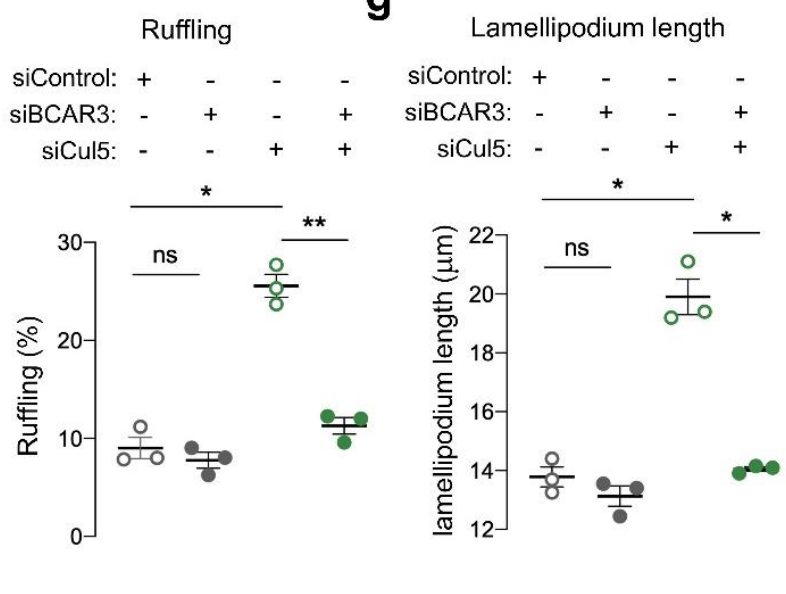

Figure 2. BCAR3 regulates epithelial cell migration. MCF10A cells were transfected with control, BCAR3 or Cul5 siRNA. (a) Representative immunoblot showing BCAR3, Cul5 and vinculin protein levels. (b) Single cell migration using Boyden chamber assay. Mean \pm SEM; $n=3$ biological replicates, each with 5 technical replicates. ${ }^{* * *} \mathrm{p}<0.0005$ and ${ }^{* * * *} p<0.0001$ (One-way ANOVA). (c) Invasion using Boyden chamber containing Matrigel. Mean $\pm S E M ; n=3$ biological replicates, each with 5 technical replicates. ${ }^{* * * *} p<0.0001$ (One-way ANOVA). (d-g) Collective migration. Confluent monolayers were placed in assay media and wounded. (d) Relative migration after 12 hours. Mean \pm SEM; $n=3$ biological replicates each with 8-12 technical replicates. ${ }^{*} p<0.05$ (One-way ANOVA). (e) Representative images of scratch wounds after 6 hours of migration. Arrows indicate cells with membrane ruffles and lines indicate lamellipodia length measurements. Scale bar: $100 \mu \mathrm{m}$. (f) Percentage of ruffling cells. Mean \pm SEM of $>250$ cells per condition from $n=3$ biological replicates. ${ }^{*} p<0.05$ and ${ }^{* *} p<0.005$ (One-way ANOVA). (g) Lamellipodia length. Mean \pm SEM of 50 cells per condition from $n=3$ biological replicates. ${ }^{*} p<0.05$ (One-way ANOVA). 


\section{Figure 2 - figure supplement 1}

a

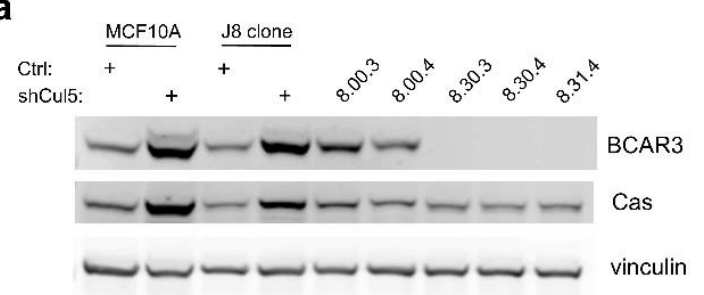

b
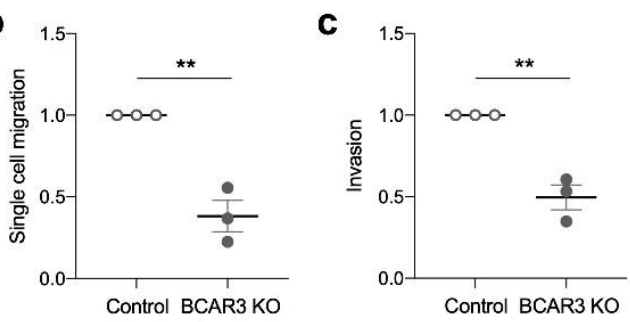

Figure 2 - figure supplement 1. BCAR3 gene deletion inhibits single-cell migration and invasion. (a) MCF10A subclone J8, selected for its epithelial morphology, was infected with an all-in-one CRISPR plasmid lacking or containing guide RNA against BCAR3 (guide 30 or 31). Potential knockouts were isolated through single cell expansion. Levels of BCAR3 and Cas in control clonal cell lines, 8.00.3 and 8.00.4, were similar to those in J8 or uncloned MCF10A cells. BCAR3-/- (KO) cell lines, 8.30.3, 8.30.4, and 8.31.4, express Cas but not BCAR3. These clones were confirmed by PCR and sequencing (Materials and Methods). (b) Single-cell migration using a Boyden chamber assay. Mean ${ }_{ \pm} S E M ; n=3 .{ }^{* *} p<0.005$ (unpaired t-test). (c) Invasion through Matrigel. Mean $\pm S E M ; n=3$. ${ }^{* *} p<0.005$ (unpaired t-test). 


\section{Figure 3}

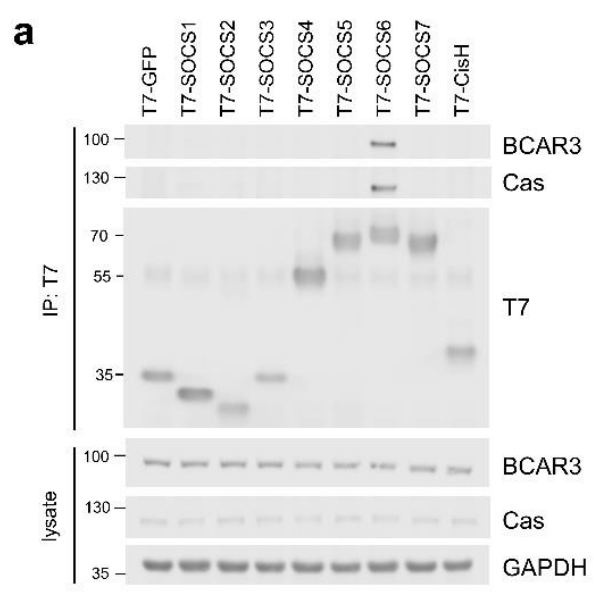

b SiRnA: Cont Cul5 SOCS6

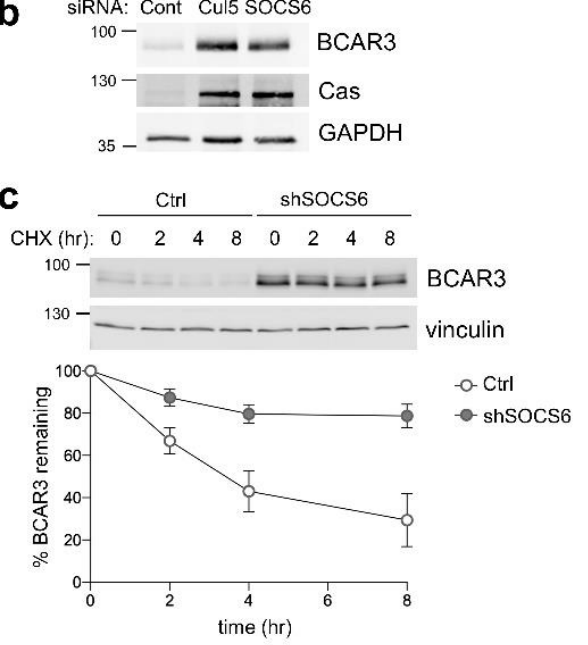

\section{d}
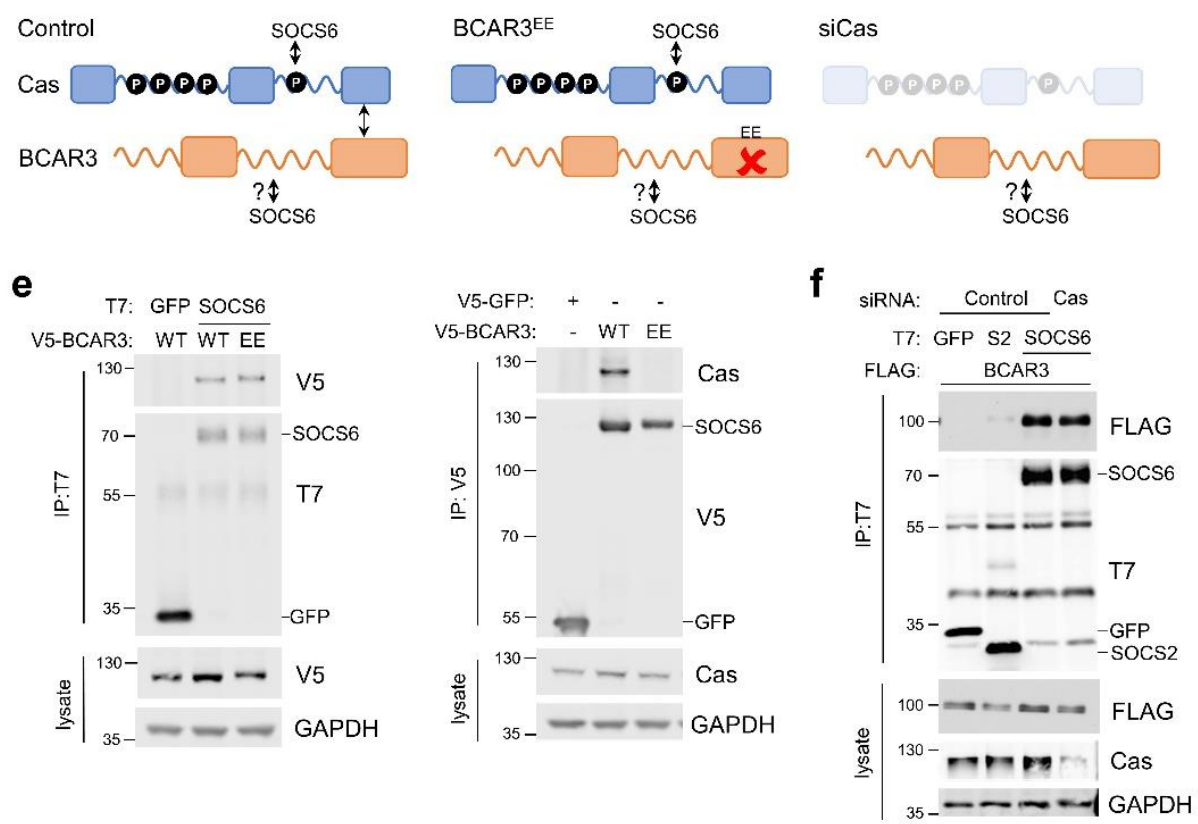

Figure 3. SOCS6 regulates BCAR3 stability independently from Cas. (a) SOCS6 binds BCAR3 and Cas. HeLa cells were transfected with T7-tagged GFP or SOCS proteins and treated with pervanadate for 30 minutes before lysis. Lysates were immunoprecipitated with $\mathrm{T} 7$ antibody and immunoprecipitates and lysates were immunoblotted with antibodies to BCAR3, Cas and T7. (b) SOCS6 regulates BCAR3 protein level. MCF10A cells were transfected with control, Cul5 or SOCS6 siRNA and analyzed by immunoblotting. (c) BCAR3 degradation. MCF10A control and SOCS6-deficient cells were treated with cycloheximide $(\mathrm{CHX})$ for various times. Representative immunoblot and quantification. Mean ${ }_{ \pm} S E M ; n=3$ biological replicates. (d) Strategy for testing whether SOCS6 binding to BCAR3 requires Cas. (e) BCAR3 LxxE/RxxE mutation inhibits binding to Cas but not SOCS6. Left panel: HeLa cells were transfected with control vector or T7-SOCS6 and SNAP-V5-BCAR3 ${ }^{\mathrm{WT}}$ or SNAP-V5-BCAR3 ${ }^{\mathrm{EE}}$. Right panel: HeLa cells were transfected with control vector, SNAP-V5-BCAR3 ${ }^{W T}$ or SNAP-V5-BCAR3EE. Lysis, immunoprecipitation and immunoblot as in (a). (f) SOCS6 binds BCAR3 in Cas-deficient cells. HeLa cells were treated with control or Cas siRNA and transfected with T7-SOCS6 and 3xFLAG-BCAR3. Lysis, immunoprecipitation and immunoblot as in (a). 


\section{Figure 4}

a

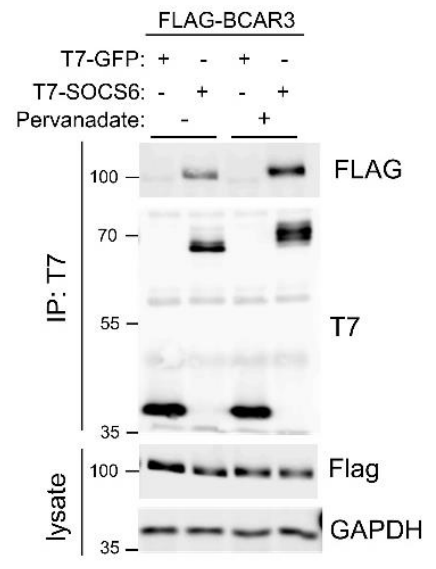

C

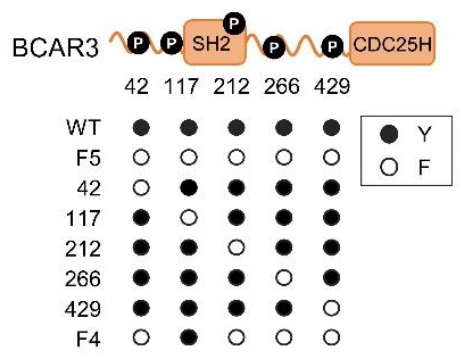

d V5-BCAR3: WT WT F5 42117212266429

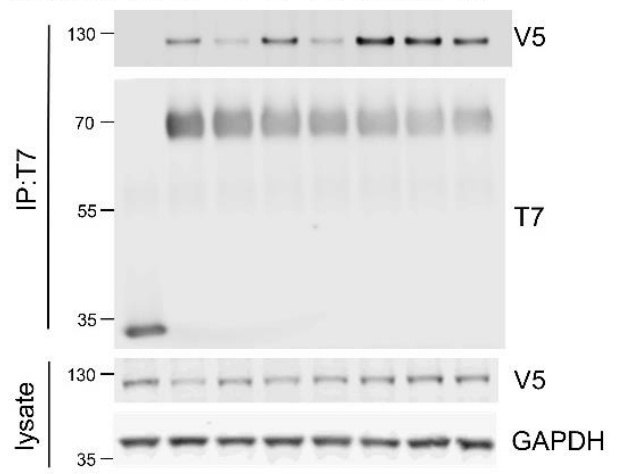

b

socse ms

$\Delta \mathrm{m}$ R407K थm

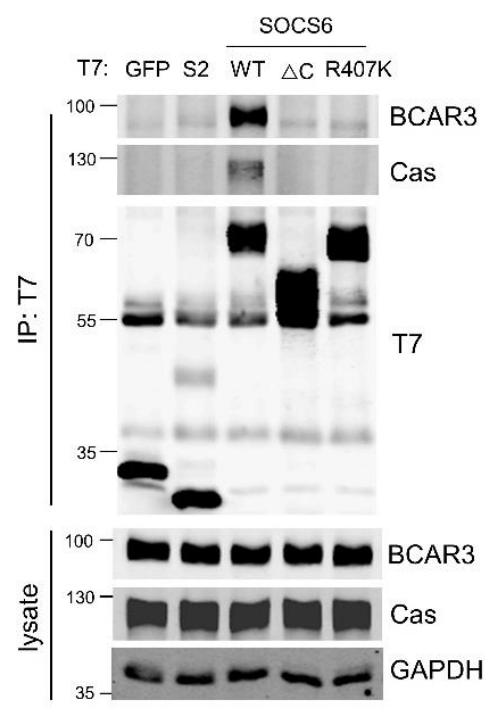

e V5-BCAR3: WT WT F5 $117 \quad$ F4

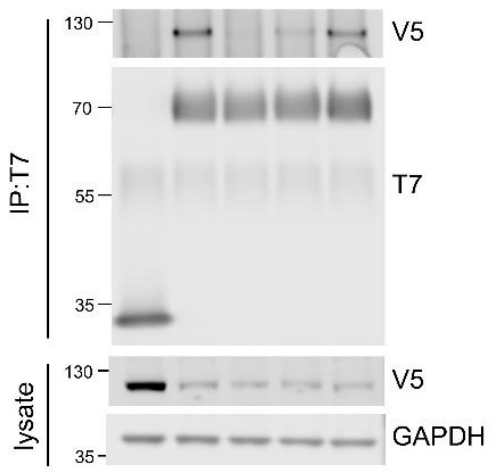

Figure 4. SOCS6 binds BCAR3 pY117. (a) Phosphatase inhibition increases SOCS6-BCAR3 binding. HeLa cells were transfected with T7-GFP or T7-SOCS6 and 3xFLAG-BCAR3 and treated with pervanadate or vehicle. Lysates were immunoprecipitated with $\mathrm{T} 7$ antibody and immunoprecipitates and lysates were immunoblotted with $\mathrm{T} 7$ and FLAG antibodies. (b) SOCS6-BCAR3 binding requires the SOCS6 SH2 domain. Cells were transfected with control vector and T7-tagged SOCS constructs, treated with pervanadate and lysed. Immunoprecipitation and immunoblotting as in (a). (c) BCAR3 ${ }^{\mathrm{WT}}$ and phenylalanine (F) mutants. Residues Y42, Y117, Y212, Y266 and Y429 phosphorylation sites have been detected across a range of cell lines (www.PhosphoSite.org). (d, e) BCAR3 Y117 is necessary and sufficient for SOCS6 binding. HeLa cells were transfected with T7-GFP or T7-SOCS6 and SNAP-V5$\mathrm{BCAR}^{\mathrm{WT}}$ or YF mutants. Transfected cells were treated with pervanadate and lysed. Immunoprecipitation and immunoblotting as in (a). 


\section{Figure 5}

a

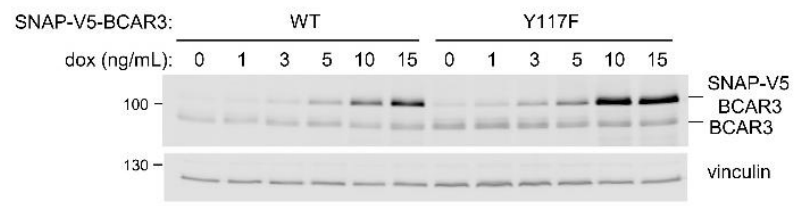

b
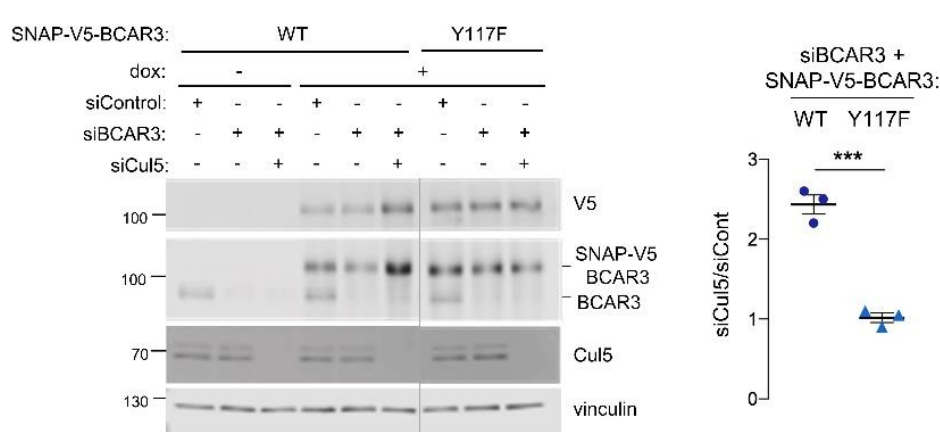

C
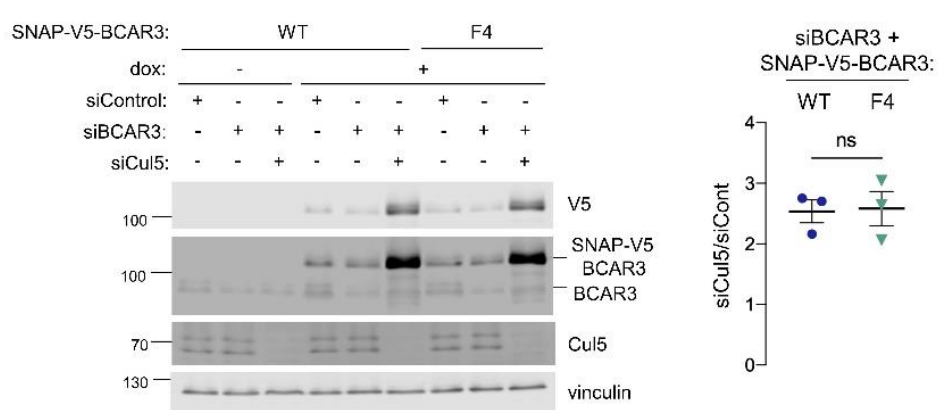

d
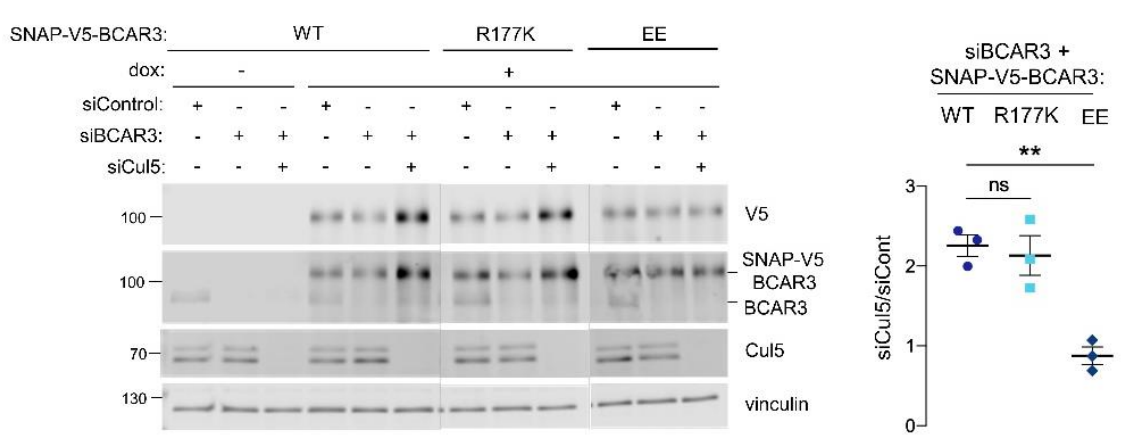

Figure 5. Cul5 requires Y117 and Cas association to regulate BCAR3 protein level. (a) Y117F mutation increases BCAR3 protein level. SNAP-V5-BCAR3WT and Y117F MCF10A cells were induced with various dox concentrations $(\mathrm{ng} / \mathrm{mL})$. Lysates were immunoblotted with BCAR3 antibody to detect endogenous and induced SNAP-V5-BCAR3. (b) Cul5 regulates BCAR3 protein level through Y117. Representative immunoblot and quantification of BCAR3 protein in siRNA-treated, dox-induced SNAP-V5-BCAR3 ${ }^{\mathrm{WT}}$ and ${ }^{\mathrm{Y} 117 \mathrm{~F}}$ cells. Mean \pm SEM; $n=3$ biological replicates. ${ }^{* *} \mathrm{p}<0.001$ by t-test. (c) Cul5 does not regulate SNAP-V5-BCAR3 ${ }^{\mathrm{F} 4}$. Mean \pm SEM; $n=3$. ns, not significant. (d) Cul5 regulates SNAP-V5-BCAR3 ${ }^{R 177 K}$ but not ${ }^{\mathrm{EE}}$. Mean $\pm \mathrm{SEM} ; \mathrm{n}=3 .{ }^{* *} \mathrm{p}<0.005$ by t-test. Vertical lines indicate different immunoblots, each run with its own wildtype control. 
bioRxiv preprint doi: https://doi.org/10.1101/2021.01.29.428899; this version posted June 9, 2021. The copyright holder for this preprint (which was not certified by peer review) is the author/funder, who has granted bioRxiv a license to display the preprint in perpetuity. It is made available under aCC-BY 4.0 International license.

Figure 5 - figure supplement 1

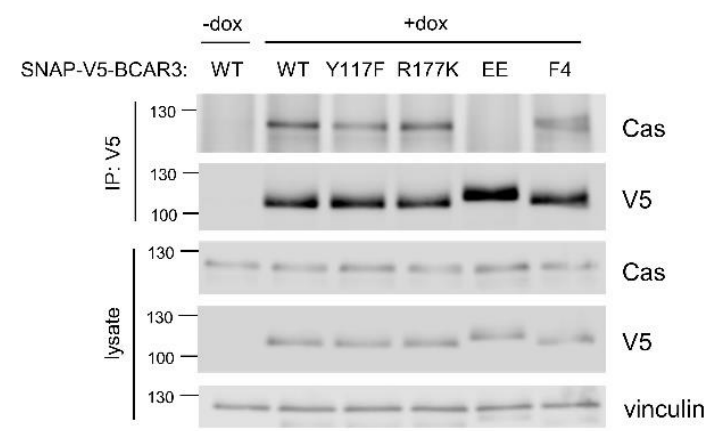

Figure 5 - figure supplement 1. Cas binding to BCAR3 mutants. SNAP-V5-BCAR3 ${ }^{\mathrm{WT}}$ and mutants were induced in MCF10A cells with $10 \mathrm{ng} / \mathrm{mL}$ dox for 48 hours. Lysates were immunoprecipitated with V5 antibody and lysates and immunoprecipitates immunoblotted with Cas and V5 antibodies. 
Figure 6

a

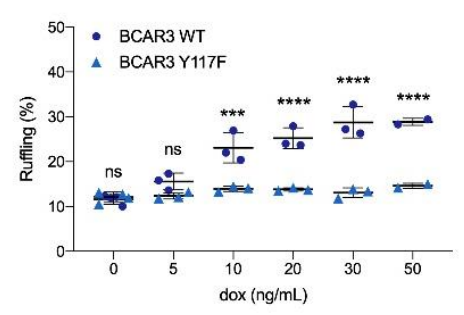

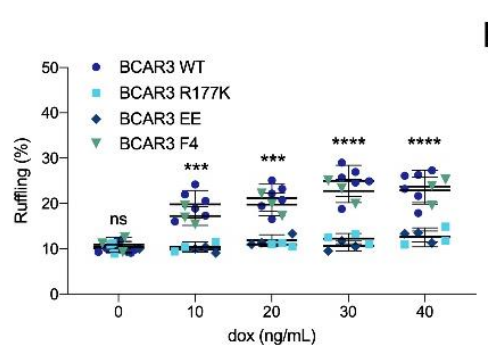

b SNAPVVSECARB:

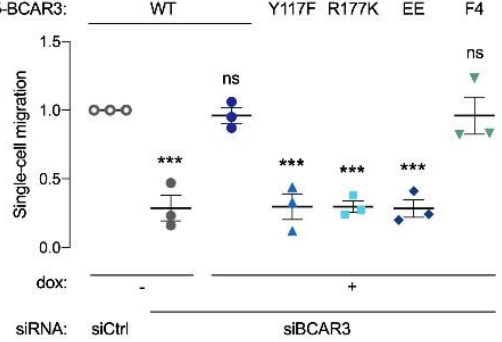

c
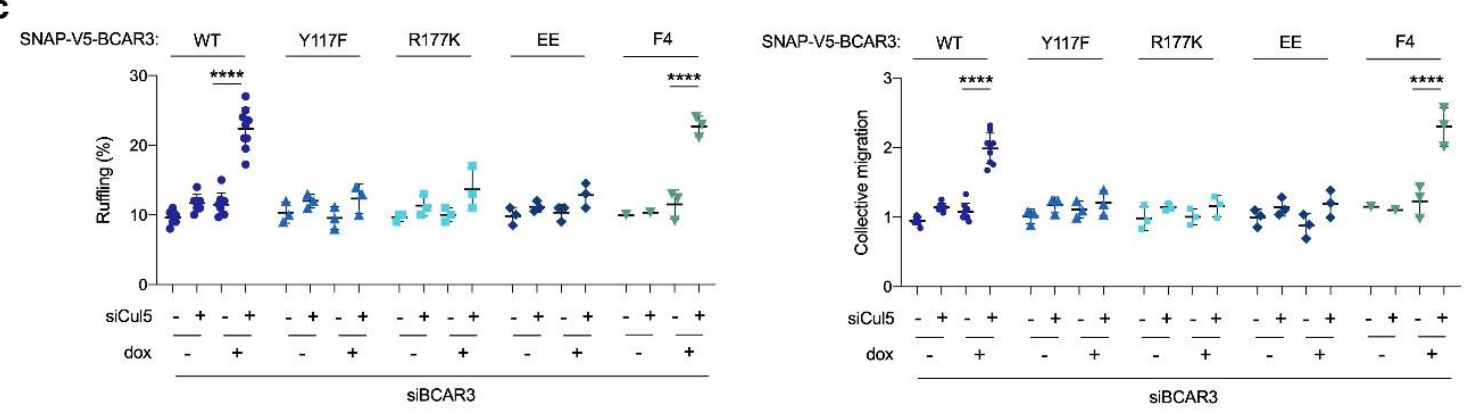

Figure 6. BCAR3 Y117, R177 and Cas binding regulate cell migration. (a) Over-expression induced ruffling. MCF10A cells transduced with wildtype or mutant SNAP-V5-BCAR3 viruses were induced with various dox concentrations $(\mathrm{ng} / \mathrm{mL})$. Confluent monolayers were starved for EGF and wounded. The percentage of ruffling cells was calculated after 6 hours. Mean \pm SEM; $n=3-6$. ${ }^{* *} p=0.0001$ and ${ }^{* * *} p<0.0001$ (One-way ANOVA). (b) Rescue of single-cell migration. Cells were treated with control or BCAR3 siRNA and expression of wildtype or mutant SNAPV5-BCAR3 induced with $10 \mathrm{ng} / \mathrm{mL}$ dox. Boyden chamber assay. Mean \pm SEM; $n=3$ biological replicates, each with 5 technical replicates. ${ }^{* * *} \mathrm{p}<0.0005$ (One-way ANOVA). (c) Rescue of Cul5-regulated ruffling and collective cell migration. Cells were treated with BCAR3 siRNA and control or Cul5 siRNA and expression of wildtype or mutant SNAP-V5-BCAR3 induced with $10 \mathrm{ng} / \mathrm{mL}$ dox. Scratch wound assay. (Left) Percentage of ruffling cells. Mean $\pm S E M$ of $>250$ cells per condition from $n=3-6$ experiments. ${ }^{* * *} p<0.0001$ (One-way ANOVA). (Right) Relative migration. Mean+SEM; $n=3-6$ biological replicates, each with 8-12 technical replicates. ${ }^{* * *} p<0.0001$ (One-way ANOVA). 
Figure 7

a

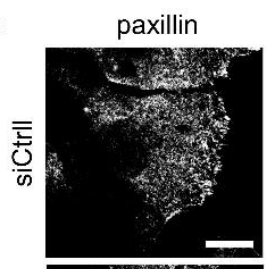

$\stackrel{m}{\stackrel{m}{\leftarrow}}$

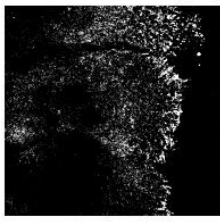

b

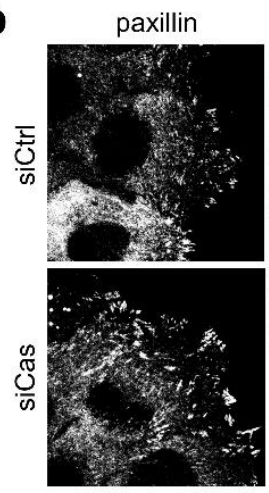

Cas
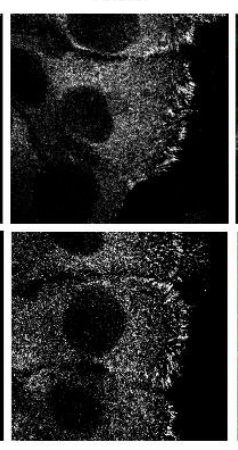

SNAP-BCAR3

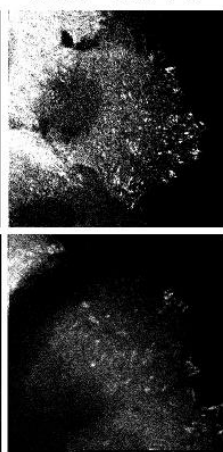

paxillin Cas
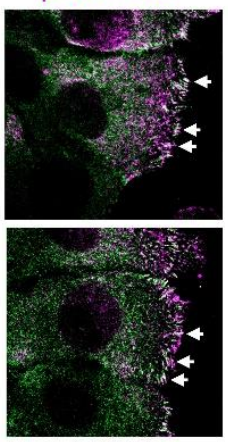

paxillin BCAR3

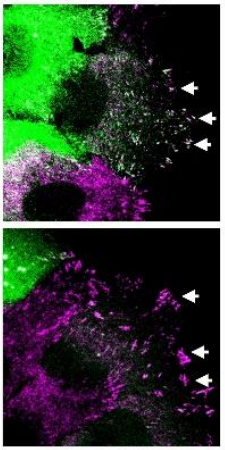

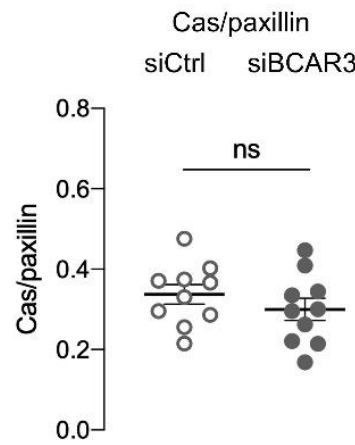

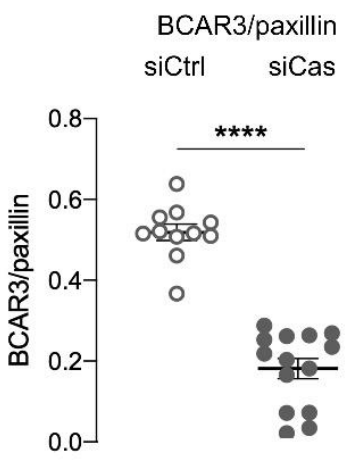

siCtrl siBCAR3

BCAR3

Cas

vinculin
siCtrl siCas

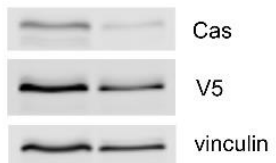

Figure 7. Cas recruits BCAR3 to adhesions. (a) Cas localization does not require BCAR3. MCF10A cells were treated with control or BCAR3 siRNA. Scratch wounds were stained for Cas and paxillin. (Left) Maximum intensity projection images. Arrowheads: adhesion sites at the leading edge. Scale bar: $10 \mu \mathrm{m}$. (Center) Mean fluorescence intensity of Cas relative to paxillin in adhesion sites at the leading edge. Mean ${ }_{ \pm} S E M ; n=10$ cells from 2 biologically independent experiments. ns, not significant. (Right) Immunoblot of Cas protein in siBCAR3-treated cells. (b) BCAR3 localization requires Cas. SNAP-V5-BCAR3 ${ }^{W T}$ MCF10A cells were treated with control or Cas siRNA and induced with $10 \mathrm{ng} / \mathrm{mL}$ dox. Scratch wounds were stained for SNAP and paxillin. (Left) Maximum intensity projection images. (Center) Mean fluorescence intensity of SNAP-BCAR3 relative to paxillin in adhesion sites at the leading edge. Mean ${ }_{ \pm} S E M ; n=11-14$ cells from 2 biologically independent experiment. ${ }^{* \star *} p<0.0001$ by unpaired $t$-test. (Right) Immunoblot of SNAP-V5-BCAR3 ${ }^{\mathrm{WT}}$ protein in siCas-treated cell. 
Figure 8

a
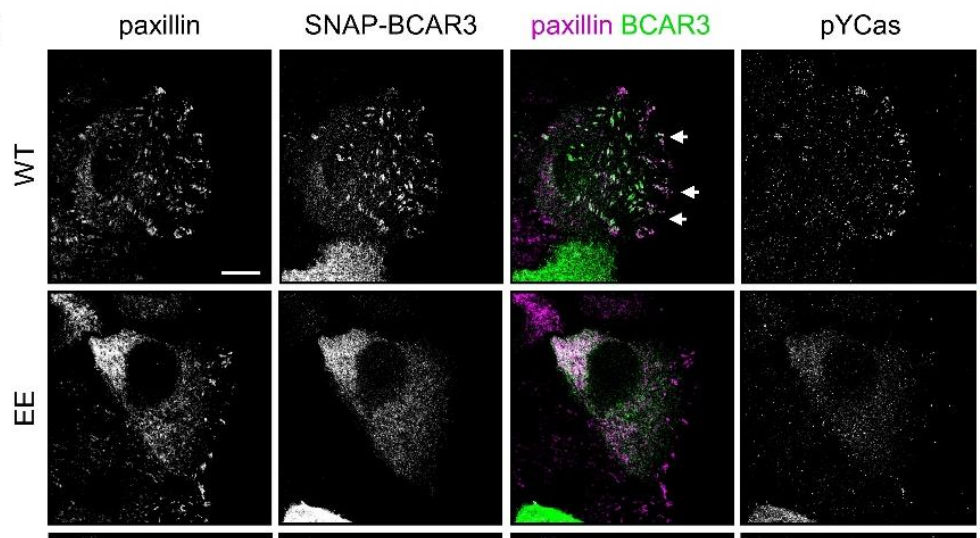

paxillin pYCas
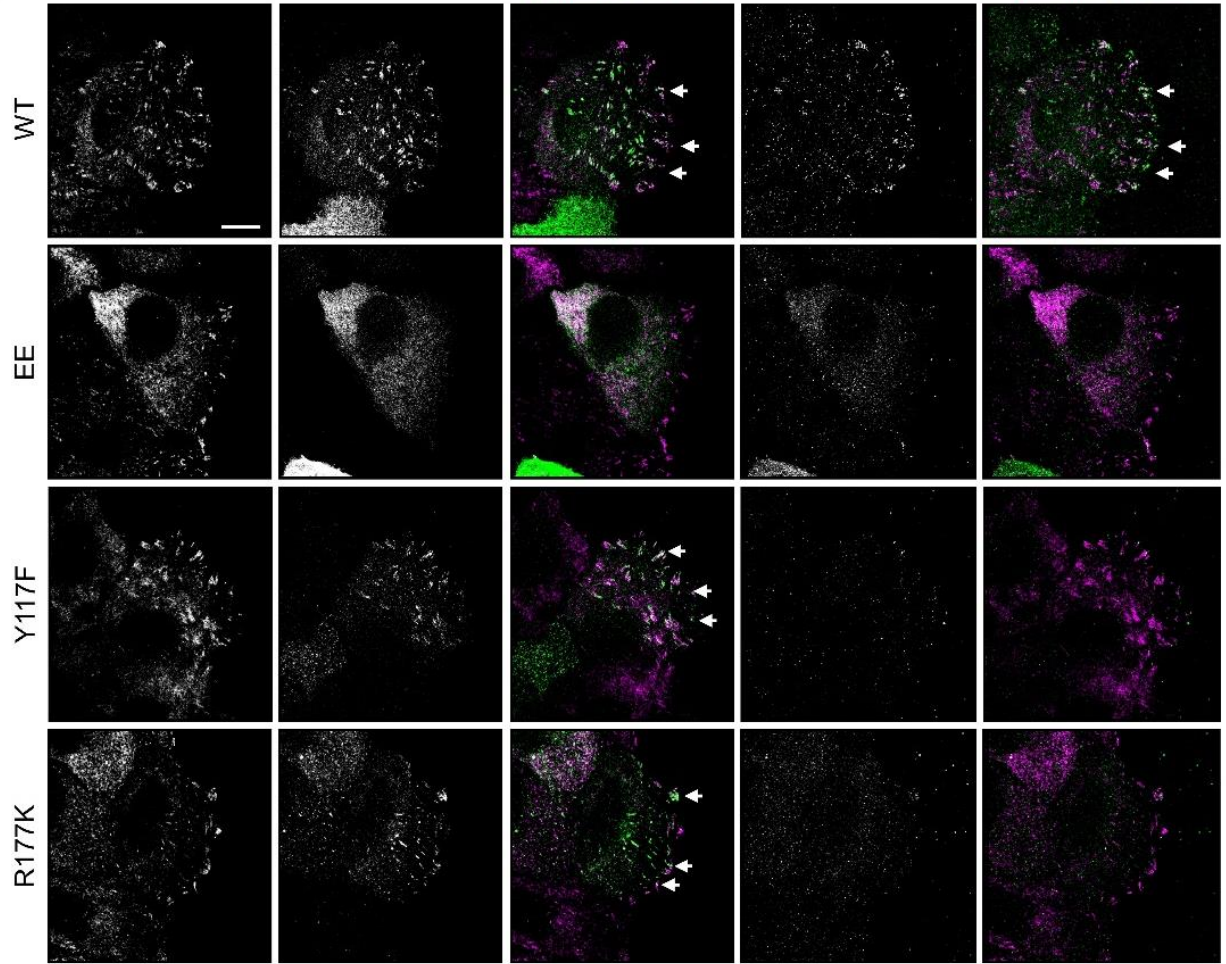

市
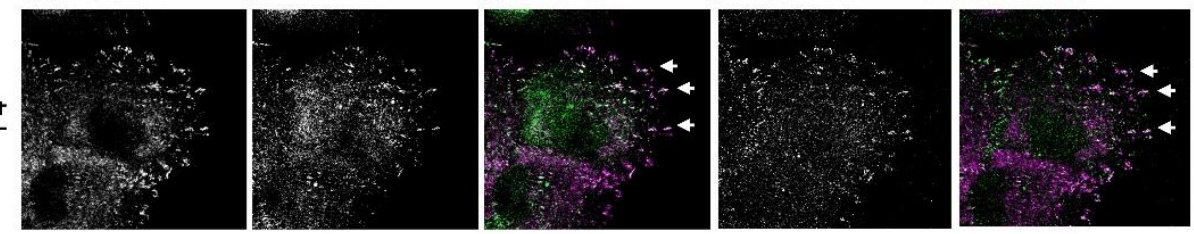

b

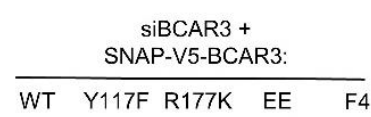

C
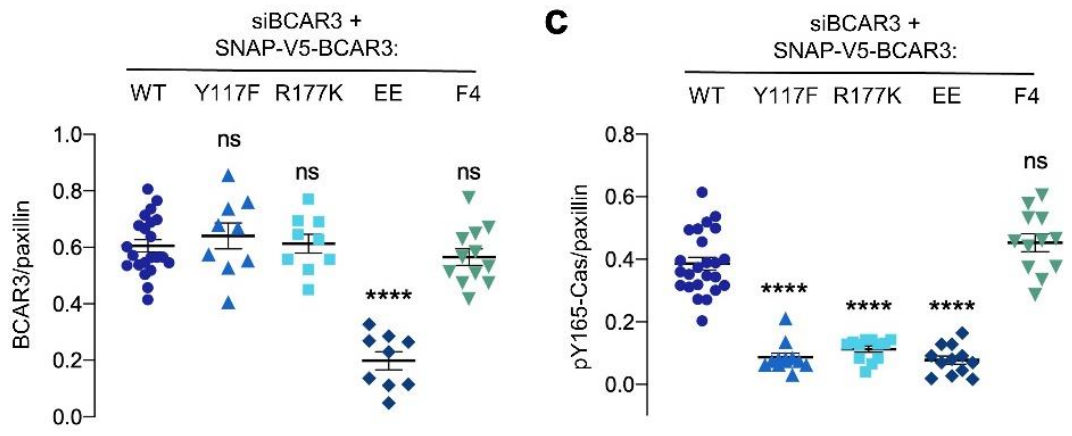

Figure 8. BCAR3 stimulates Cas phosphorylation in adhesions, dependent on BCAR3 Y117 and SH2

interactions. (a) Wildtype or mutant SNAP-V5-BCAR3 MCF10A cells were treated with control or BCAR3 siRNA and induced with $10 \mathrm{ng} / \mathrm{mL}$ dox. Scratch wound were stained for SNAP, pY165-Cas and paxillin. Maximum intensity projection. Scale bar $=10 \mu \mathrm{m}$. (b) Mean fluorescence intensity of SNAP-V5-BCAR3 relative to paxillin in adhesion sites at the leading edge. Mean \pm SEM. ${ }^{* * *} p<0.0001$ (One-way ANOVA). (c) Mean fluorescence intensity of pY165Cas relative to paxillin in adhesion sites at the leading edge. Mean \pm SEM. ${ }^{* \star *} p<0.0001$ (One-way ANOVA). 
Figure 8 - figure supplement 1

a
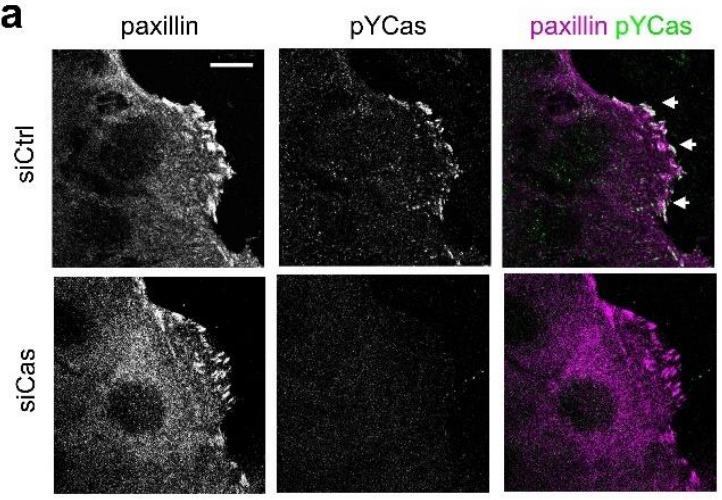

b
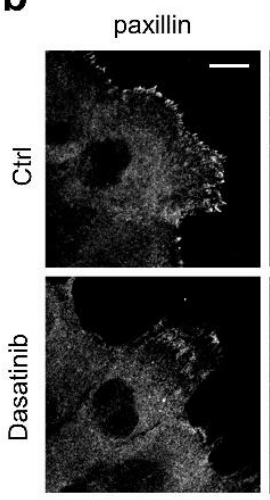

paxillin pYCas
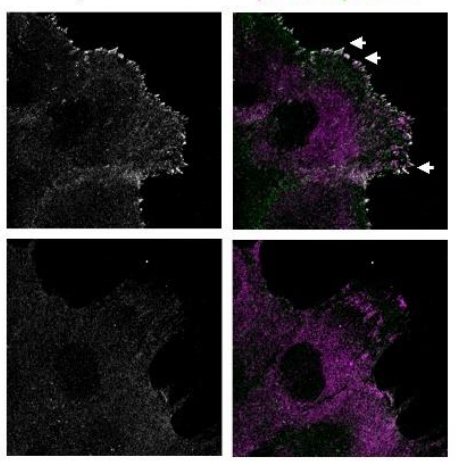

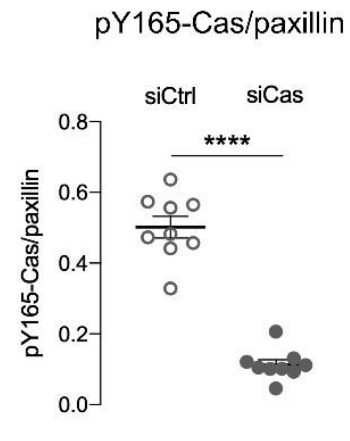

pY165-Cas/paxillin

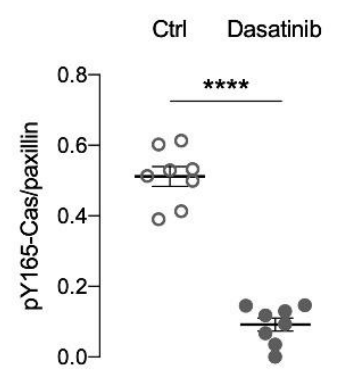

Figure 8 - figure supplement 1 . The pY165-Cas antibody is specific for pYCas. MCF10A scratch wounds were stained for pY165-Cas and paxillin. (a) Cas siRNA inhibits pY165-Cas immunofluorescence. (b) Dasatinib inhibits pY165-Cas immunofluorescence. (Left) Maximum intensity projection images. Scale bar $=10 \mu \mathrm{m}$. (Right) Mean fluorescence intensity of $\mathrm{pY} 165$-Cas relative to paxillin in adhesion sites at the leading edge. Mean \pm SEM; $n=8-9$ cells from 1 experiment. ${ }^{* * *} \mathrm{p}<0.0001$ unpaired t-test. 
Figure 8 - figure supplement 2

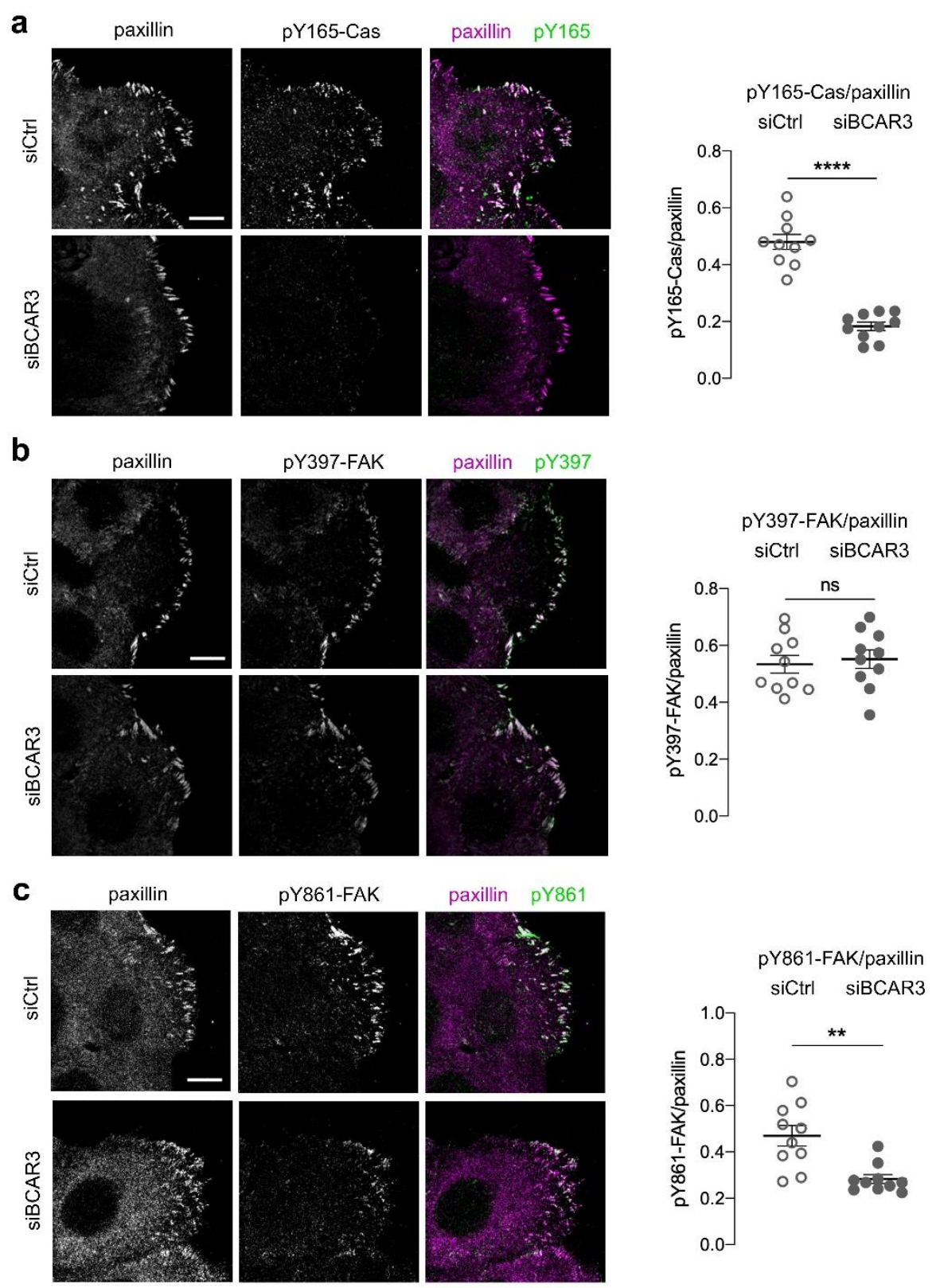

Figure 8 - figure supplement 2. BCAR3 is required for pY165-Cas and pY861-FAK, but not pY397-FAK. Control or BCAR3-depleted MCF10A scratch wounds were stained for paxillin and (a) pY165-Cas, (b) pY397-FAK or (c) pY861-FAK. (Left) Maximum intensity projection images. Scale bar $=10 \mu \mathrm{m}$. (Right) Mean fluorescence intensity of (a) pY165-Cas, (b) pY397-FAK or (c) pY861-FAK relative to paxillin in adhesion sites at the leading edge. Mean $\pm S E M ; n=10$ cells from 1 experiment. ${ }^{* *} p<0.01,{ }^{* * * *} p<0.0001$ and $p>0.05$ by unpaired $t$-test. 
bioRxiv preprint doi: https://doi.org/10.1101/2021.01.29.428899; this version posted June 9, 2021. The copyright holder for this preprint (which was not certified by peer review) is the author/funder, who has granted bioRxiv a license to display the preprint in perpetuity. It is made available under aCC-BY 4.0 International license.

Figure 8 - figure supplement 3

a
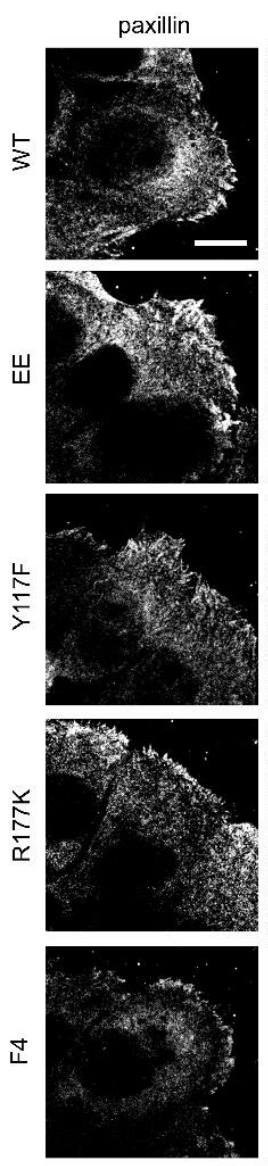

SNAP-BCAR3
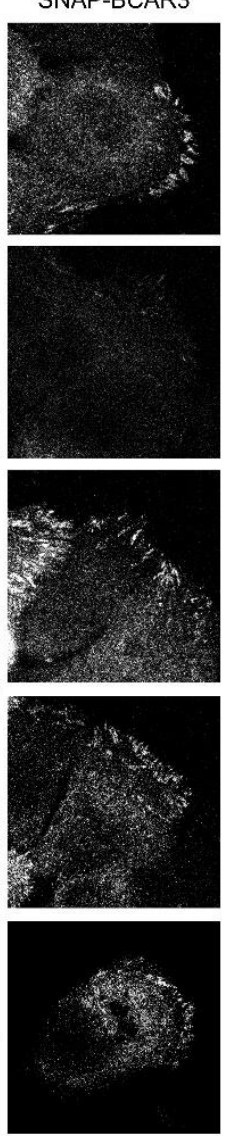

Cas
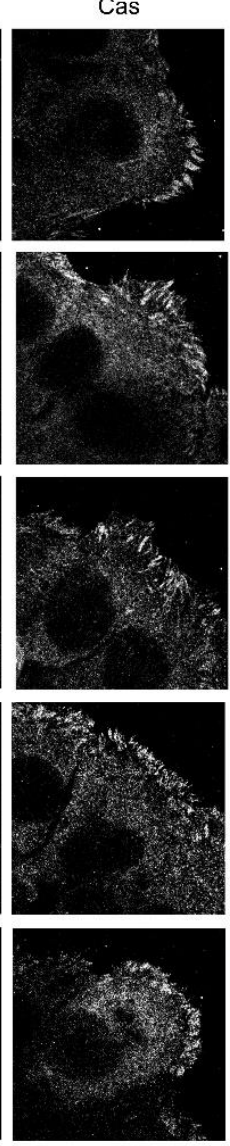

paxillin Cas
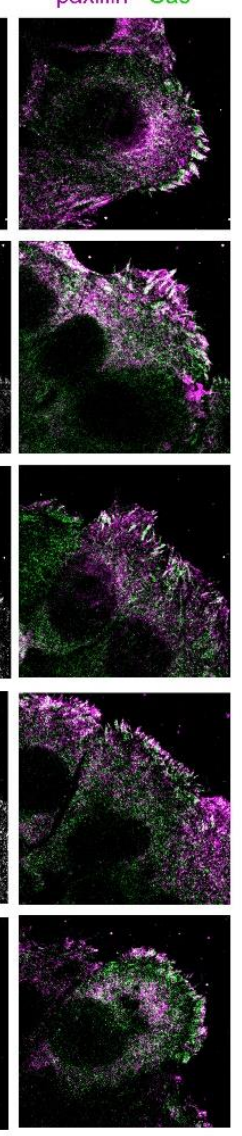

b

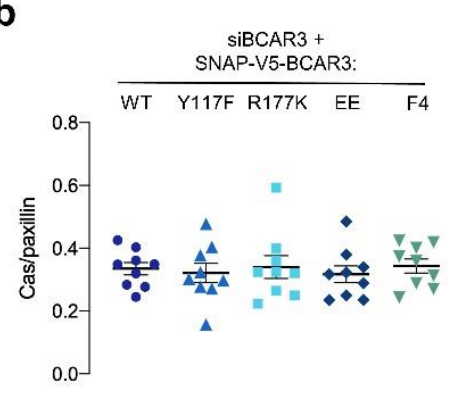

C
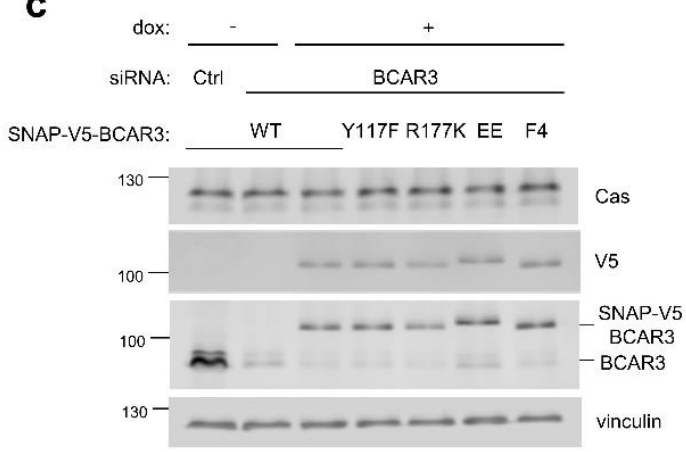

Figure 8 - figure supplement 3. Cas levels are not altered when BCAR3 ${ }^{W T}$ and mutants are expressed. (a) Wildtype or mutant SNAP-V5-BCAR3 MCF10A cell scratch wounds were stained for Cas and paxillin. Maximum intensity projection. Scale bar $=10 \mu \mathrm{m}$. (b) Mean fluorescence intensity of Cas relative to paxillin in adhesion sites at the leading edge. Mean \pm SEM. P $>0.05$ (One-way ANOVA). (c) Immunoblot of Cas and BCAR3 in siRNA-treated, doxinduced SNAP-V5-BCAR3 ${ }^{\mathrm{WT}}$ and mutant cells. 
Figure 9

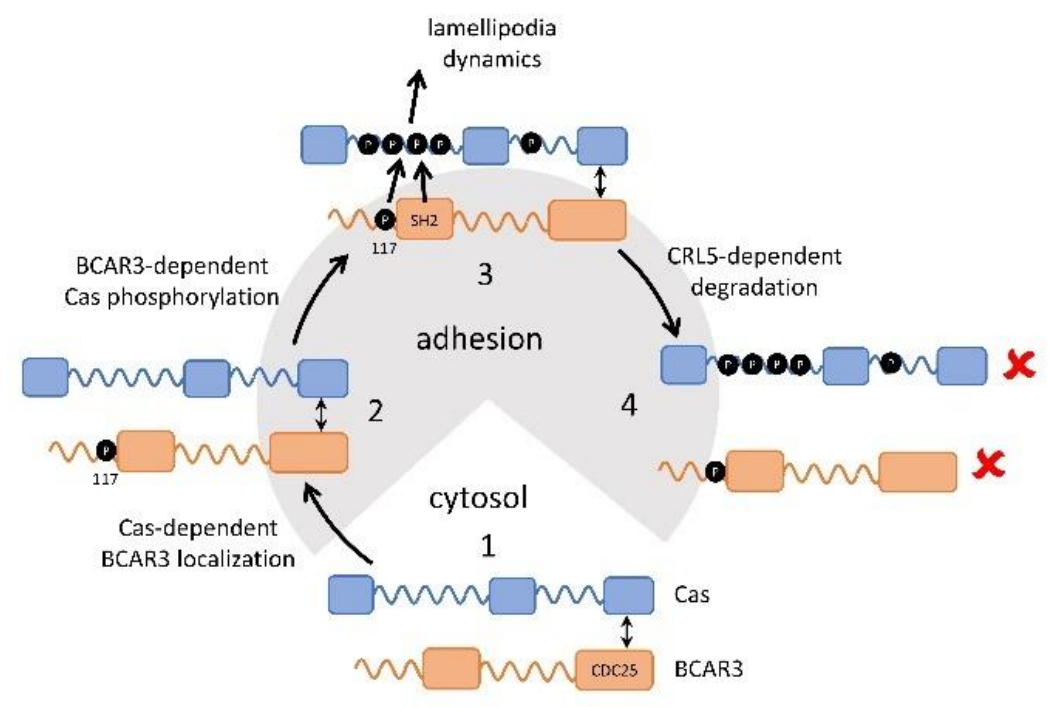

Figure 9. Model showing inter-dependence of Cas and BCAR3 for localization and activation. Step 1: A preformed BCAR3-Cas complex translocates to integrin adhesions through localization signals in the $\mathrm{N}$ and $\mathrm{C}$ terminal domains of Cas. Step 2: BCAR3, phosphorylated at $Y 117$ by an unknown kinase, stimulates Cas phosphorylation in a process that also requires the $\mathrm{SH} 2$ domain, leading to activation of signaling pathways that stimulate lamellipodial

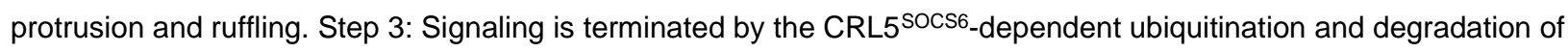
BCAR3, phosphorylated in their respective phosphodegrons. Remaining questions include the identity of the kinase that phosphorylates BCAR3 Y117, the timing of Y117 phosphorylation, and the mechanism by which BCAR3 pY117 and $\mathrm{SH} 2$ domain stimulate Cas phosphorylation. 
bioRxiv preprint doi: https://doi.org/10.1101/2021.01.29.428899; this version posted June 9, 2021. The copyright holder for this preprint (which was not certified by peer review) is the author/funder, who has granted bioRxiv a license to display the preprint in perpetuity. It is made available under aCC-BY 4.0 International license.

\section{Figure 9 - figure supplement 1}

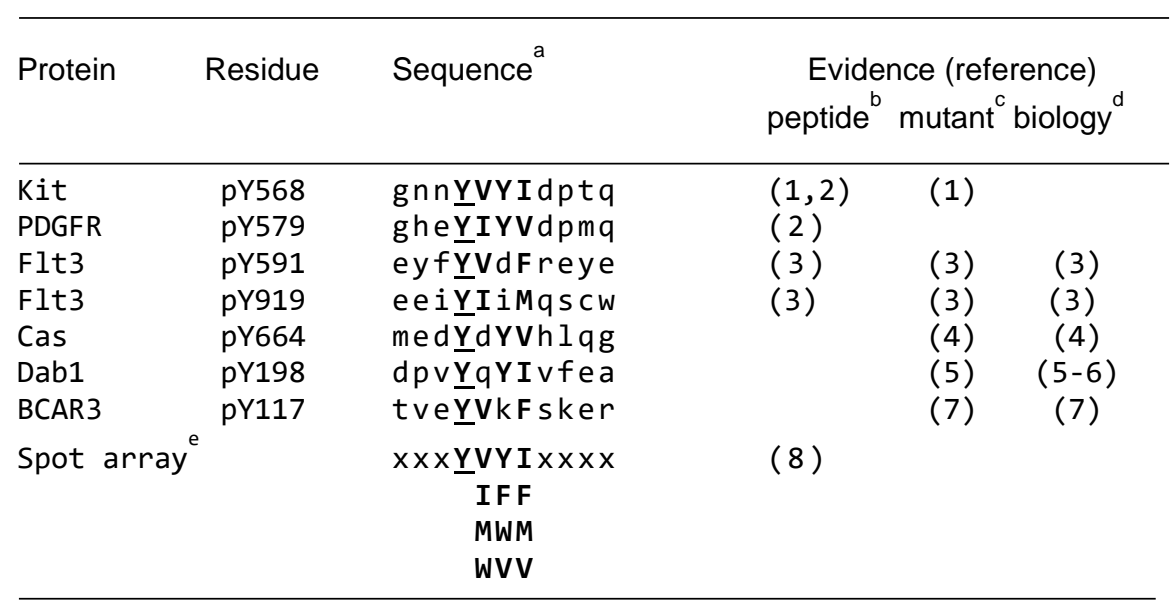

Figure 9 - figure supplement 1. Sequence alignment of SOCS6 binding sites.

${ }^{a}$ Local sequence aligned to phosphotyrosine $(Y)$. Capital letters indicate residues at +1 to +3 positions that fit the consensus from the spot array.

${ }^{b}$ Phosphopeptide binds to SH2 domain in vitro

${ }^{c}$ Decreased binding of $\mathrm{Y}$ to $\mathrm{F}$ mutant protein in cells

${ }^{d} Y$ to $F$ mutant is stabilized or gains function in cells

e A library of phosphopeptides randomized at positions +1 to +3 was selected by binding to the SOCS6 SH2 domain. Bound peptides were sequenced. Residues selected at each position are shown in decreasing order of preference.

References: (1) (Bayle et al., 2004) (2) (Zadjali et al., 2011) (3) (Kazi et al., 2012) (4) (Teckchandani et al., 2014) (5) (Feng et al., 2009) (6) (Simo et al., 2013) (7) this work, (8) (Krebs et al., 2002). 
bioRxiv preprint doi: https://doi.org/10.1101/2021.01.29.428899; this version posted June 9, 2021. The copyright holder for this preprint (which was not certified by peer review) is the author/funder, who has granted bioRxiv a license to display the preprint in perpetuity. It is made available under aCC-BY 4.0 International license.

\section{Supplementary Material}

Supplementary Table 1. Quantification of phosphotyrosine peptides in control and Cul5deficient MCF10A cells. Phosphopeptides whose abundance significantly differed between control and Cul5-deficient MCF10A cells in two separate experiments. Sheet 1: Experimental conditions, numbers of phosphopeptides quantified, and number of significant changes. Sheet 2: Phosphopeptides significantly increased in Experiment 1. Sheet 3: Phosphopeptides significantly increased in Experiment 2. Sheet 4: Phosphopeptides significantly increased in both Experiments (see also Figure 1 - Figure Supplement 1). 